\title{
HERANÇA E CUSTO ADAPTATIVO DA RESISTÊNCIA DE Spodoptera frugiperda (Lepidoptera: Noctuidae) AO PIRETRÓIDE LAMBDA-CIALOTRINA
}

\section{GABRIELA INÉS DIEZ-RODRÍGUEZ}

Engenheiro Agrônomo

Orientador: Prof. Dr. CELSO OMOTO

Dissertação apresentada à Escola Superior de
Agricultura "Luiz de Queiroz", Universidade de
São Paulo, para obtenção do título de Mestre em
Ciências, Área de Concentração: Entomologia.

P I R A C I C A B A

Estado de São Paulo - Brasil

Julho -2000 


\section{Dados Internacionais de Catalogaçāo na Publicação (CIP) DIVISĀO DE BIBLIOTECA E DOCUMENTAÇĀO - Campus "Luiz de Oueiroz"/USP}

Diez-Rodriguez, Gabriela Inés

Herança e custo adaptativo da resistência de Spodoptera frugiperda (Lepidoptera Noctuidae) ao piretróide lambda-cialotrina / Gabriela Inés Diez-Rodriguez. - - Piracicaba, 2000.

$57 \mathrm{p}$.

Dissertação (mestrado) - - Escola Superior de Agricultura Luiz de Queiroz, 2000.

Bibliografia.

1. Inseticida piretróide 2. Lagarta-do-cartucho 3. Lepidoptera 4. Resistência genética 5. Resistência ao inseticida I. Titulo

$\operatorname{CDD} 632.78$

Termitida a copia total ou parcial deste documento, desde que citada a fonte- 0 autom? 


\section{AOS MEUS AVÔS,}

CARLOS ENRIQUE E ALICIA LAURA

(in memorian)

AOS MEUS PAIS,

LUCAS MARIO E RAQUEL ALICIA,

OFEREÇO

AS MINHAS IRMÃS,

INDIANA, MARIANA E MARIA FLORENCIA, DEDICO 


\section{AGRADECIMENTOS}

Ao Prof. Dr. Celso Omoto, pela oportunidade, amizade e ensinamentos transmitidos no decorrer do curso.

Aos Professores do Curso de Pós-Graduação em Entomologia da ESALQ/USP, pelos valiosos conhecimentos transmitidos.

À Fundação de Amparo à Pesquisa do Estado de São Paulo - FAPESP (Processo \#1998/02937-8), pela concessão da bolsa de estudos para a execução deste trabalho.

Aos meus pais e avôs (in memoriam) pelo exemplo de vida e honestidade, pelo amor e por estarem sempre junto a mim apesar das distâncias.

As minhas irmãs, cunhados e sobrinhos pelo carinho e apoio.

Ao colega Dori Edson Nava, pelo carinho e incentivo.

Aos colegas do Curso de Pós-Graduação em Entomologia pela amizade e companheirismo.

Aos amigos María del Carmen Ferragine, Carlos Giaveno e Silvia Imhoff pela amizade e colaboração em todos os momentos que foram necessários.

Ao pessoal do Laboratório de "Resistência de Artrópodos a Pesticidas" pelo agradável convívio, em especial ao Sr. Francisco Castillo.

Aos colegas Enrique Castiglione, Paulo Bogorni, Everaldo Batista Alves e Eloisa Salmerón pelas sugestões para a melhora deste trabalho 
Ao Dr. Guillermo Videla e família, pelo apoio e incentivo.

Às bibliotecárias da Prefeitura do Campus de Piracicaba da ESALQ/USP pela correção das referências bibliográficas, em particular à Silvia Zinsly.

A todos aqueles que direta ou indiretamente colaboraram para a execução deste trabalho. 


\section{SUMÁRIO}

Página

LISTA DE FIGURAS.................................................................. viii

LISTA DE TABELAS ........................................................... ix

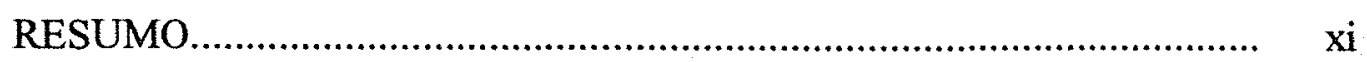

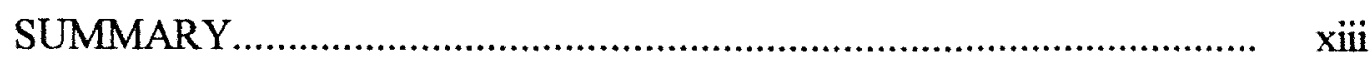

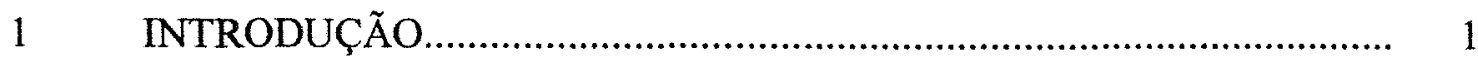

2 REVISÃO DE LITERATURA.................................................... 3

2.1 Resistência de Spodoptera frugiperda a inseticidas............................... 3

2.2 Genética da resistência de lepidópteros a pesticidas................................. 4

2.3 Custo adaptativo da resistência de pragas a pesticidas........................... 7

2.4 Biologia de Spodoptera frugiperda em dietas artificiais......................... 12

3 MATERIAL E MÉTODOS........................................................... 15

Criação de Spodoptera frugiperda em laboratório............................... 16

3.1.1 Criação para a manutenção das populações.......................................... 16

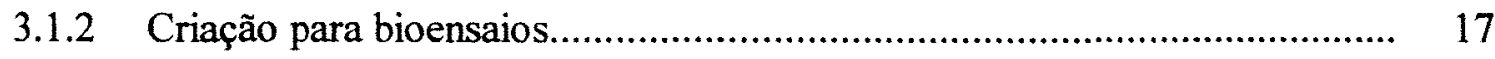

Procedimentos de bioensaio............................................................ 18

3.3 Caracterização da resistência de Spodoptera frugiperda à lambdacialotrina................................................................................ 18

3.4 Herança da resistência de Spodoptera frugiperda à lambdacialotrina.

3.5 Custo adaptativo da resistência de Spodoptera frugiperda à lambdacialotrina.................................................................................... 21

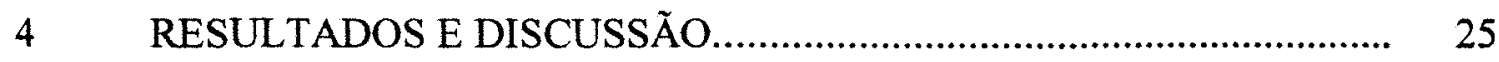

4.1 Caracterização da resistência de Spodoptera frugiperda à lambda-

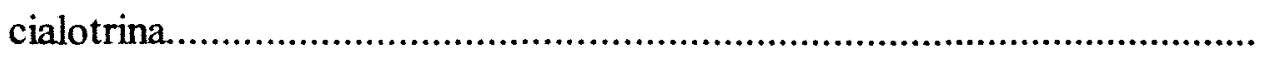

4.2 Herança da resistência de Spodoptera frugiperda à lambdacialotrina.. 
4.2.1 Dominância da resistência.................................................................... 29

4.2.2 Número de genes.............................................................................. 31

4.3 Custo adaptativo da resistência de Spodoptera frugiperda à lambda-

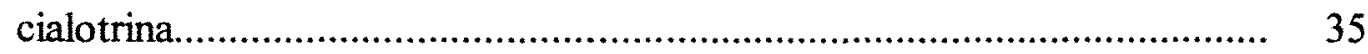

5 CONCLUSÕES 44

REFERÊNCIAS BIBLIOGRÁFICAS.................................................. 45 


\section{LISTA DE FIGURAS}

Página

1 Curvas de concentração-resposta da população GUA de $S$. frugiperda e da linhagem resistente $(\mathrm{R})$ obtida após 6 ciclos de seleção da população GUA com lambda-cialotrina.

2 Curvas de concentração-resposta das linhagens susceptível (S) e resistente (R) de $S$. frugiperda à lambda-cialotrina

3 Curvas de concentração-resposta ao inseticida lambda-cialotrina para as linhagens de $S$. frugiperda susceptível (S), resistente (R), progênies de $F_{1}$ e retrocruzamento $\left(F_{1} \times R\right)$. Mortalidades esperadas e observadas nos retrocruzamentos são representadas pelos símbolos respectivamente. 


\section{LISTA DE TABELAS}

Página

1 Composição da dieta artificial utilizada para criação de $S$. frugiperda em laboratório (modificada de Perkins et al., 1973)......................................... 16

2 Respostas das $F_{1}$ resultantes de cruzamentos entre as linhagens $S$ e $R$ de S. frugiperda à lambda-cialotrina.

3 Qui-quadrado entre as mortalidades observadas e esperadas dos retrocruzamentos $\left(\begin{array}{lllllll}F_{1} & x & R\end{array}\right)$ para $\quad 0 \quad$ modelo monogênico (g.l. $=1)$

4 Duração média \pm erro padrão (em dias) e viabilidade (\%) da fase de larva das linhagens de $S$. frugiperda susceptível $(\mathrm{S}), \mathrm{F}_{1}$ e isogênica- $\mathrm{R}$, à temperatura de $25 \pm 1^{\circ} \mathrm{C}$, UR de $70 \pm 10 \%$ e fotofase de 14 horas.

5 Duração média \pm erro padrão (em dias) de pupas por sexo das linhagens de $S$. frugiperda susceptível (S), $\mathrm{F}_{1}$ e isogênica-R, à temperatura de $25 \pm$ $1{ }^{\circ} \mathrm{C}$, UR de $70 \pm 10 \%$ e fotofase de 14 horas.

6 Viabilidade (\%) e razão sexual da fase de pupa das linhagens de $S$. frugiperda susceptível $(\mathrm{S}), \mathrm{F}_{1}$ e isogênica-R, à temperatura de $25 \pm 1^{\circ} \mathrm{C}$, UR de $70 \pm 10 \%$ e fotofase de 14 horas

7 Peso médio \pm erro padrão (em $\mathrm{mg}$ ) de pupas por sexo das linhagens de $S$. frugiperda susceptível (S), $F_{1}$ e isogênica- $R$, à temperatura de $25 \pm 1^{\circ} \mathrm{C}$, UR de $70 \pm 10 \%$ e fotofase de 14 horas 
8 Longevidade média \pm erro padrão (em dias) de adultos por sexo das linhagens de $S$. frugiperda susceptível $(\mathrm{S}), \mathrm{F}_{1}$ e isogênica- $\mathrm{R}$, à temperatura de $25 \pm 1^{\circ} \mathrm{C}$, UR de $70 \pm 10 \%$ e fotofase de 14 horas..............

9 Número médio de ovos por fềmea \pm erro padrão das linhagens de $S$. frugiperda susceptível (S), $\mathrm{F}_{1}$ e isogênica-R, à temperatura de $25 \pm 1^{\circ} \mathrm{C}$, UR de $70 \pm 10 \%$ e fotofase de 14 horas

10 Duração média \pm erro padrão (em dias) dos periodos de pré-oviposição e oviposição das linhagens de $S$. frugiperda susceptivel (S), $F_{1}$ e isogênica$\mathrm{R}$, à temperatura de $25 \pm 1{ }^{\circ} \mathrm{C}$, UR de $70 \pm 10 \%$ e fotofase de 14 horas.

11 Duração média \pm erro padrão (em dias) e viabilidade (\%) da fase de ovo das linhagens de $S$. frugiperda susceptivel (S), $\mathrm{F}_{1}$ e isogênica-R, à temperatura de $25 \pm 1^{\circ} \mathrm{C}$, UR de $70 \pm 10 \%$ e fotofase de 14 horas.

12 Duração média \pm erro padrão (em dias) do periodo ovo-adulto das linhagens de $S$. frugiperda susceptível (S), $F_{1}$ e isogênica-R, à temperatura de $25 \pm 1{ }^{\circ} \mathrm{C}$, UR de $70 \pm 10 \%$ e fotofase de 14 horas.

13 Parâmetros biológicos obtidos através da tabela de vida de fertilidade para as linhagens de $S$. frugiperda susceptível (S), $\mathrm{F}_{1}$ e isogênica-R: duração média de uma geração $(T)$, taxa líquida de reprodução $\left(R_{0}\right)$, capacidade inata de aumentar em número $\left(r_{m}\right)$ e razão finita de aumento $(\lambda) \ldots \ldots \ldots \ldots . . . . . .$. 


\section{HERANÇA E CUSTO ADAPTATIVO DA RESISTÊNCIA DE Spodoptera frugiperda (LEPIDOPTERA: NOCTUIDAE) AO PIRETRÓIDE LAMBDA- CIALOTRINA}

Autor: Gabriela Inés Diez-Rodriguez

Orientador: Prof. Dr. Celso Omoto

\section{RESUMO}

A herança e o custo adaptativo da resistência de Spodoptera frugiperda (J.E. Smith) ao inseticida piretróide lambda-cialotrina foram avaliados no presente estudo. Uma intensidade de resistência de aproximadamente 13 vezes foi detectada em uma linhagem resistente de $S$. frugiperda selecionada no laboratório com lambda-cialotrina. Cruzamentos recíprocos entre as linhagens susceptivel (S) e resistente (R) de $S$. frugiperda à lambda-cialotrina revelaram o caráter autossomal e incompletamente recessivo da resistência. Resultados dos retrocruzamentos da progênie $F_{1}$ (heterozigota) com o parental resistente sugeriram que a resistência foi determinada por um gene principal sob a influência de genes secundários. Para avaliar o custo adaptativo dos indivíduos resistentes, uma linhagem isogênica (isogênica- $R$ ) foi criada através de uma série de cruzamentos entre as linhagens $\mathrm{S}$ e $\mathrm{R}$ para a obtenção da progênie heterozigota, e seguidos de um intercruzamento dessa progênie para $o$ isolamento de indivíduos resistentes homozigotos, e posterior retrocruzamento desses individuos com a linhagem S. Avaliações de parâmetros biológicos das linhagens $S$, isogênica- $R$ e $F_{1}$ revelaram a inexistência de custo adaptativo da resistência de $S$. frugiperda à lambda-cialotrina. 
Implicações dos resultados obtidos para o manejo da resistência de $S$. frugiperda a esse inseticida foram discutidas. 


\title{
INHERITANCE AND FITNESS COST ASSOCIATED WITH RESISTANCE OF Spodoptera frugiperda (LEPIDOPTERA: NOCTUIDAE) TO LAMBDA- CYHALOTHRIN
}

\author{
Author: Gabriela Inés Diez-Rodríguez \\ Adviser: Prof. Dr. Celso Omoto
}

\section{SUMMARY}

Inheritance and fitness cost associated with resistance of Spodoptera frugiperda (J.E. Smith) to the pyrethroid insecticide lambda-cyhalothrin were evaluated in this study. An intensity of resistance of approximately 13 -fold was detected in a laboratory-selected resistant strain of $S$. frugiperda to lambda-cyhalothrin. Reciprocal crosses between susceptible (S) and resistant (R) strains of $S$. frugiperda to lambda-cyhalothrin revealed that the resistance was autossomal and incompletely recessive. Results from the backcross of $F_{1}$ progenie to the $R$ strain suggested that the resistance was determined by a single major gene under a influence of some minor genes. To evaluate the fitness cost associated with the resistance, an isogenic resistant strain (isogenic- $R$ ) was built by a series of crosses between $S$ and $R$ strains to obtain the $F_{1}$ progenie followed by the intercross of $F_{1}$ to isolate the resistant individuals for further backcross to $S$ strain. Evaluation of biological parameters of $S$, isogenic-R and $F_{1}$ strains showed no fitness cost associated with the resistance of $S$. frugiperda to lambda-cyhalothrin. Implications of these results for insecticide resistance management of $S$. frugiperda to this insecticide were discussed. 


\section{INTRODUÇÃO}

A lagarta-do-cartucho, Spodoptera frugiperda (J.E. Smith, 1797), é uma das principais pragas da cultura do milho no Brasil. Com a introdução do milho "safrinha" e o plantio na época de inverno em regiões com infra-estrutura de irrigação, os problemas fitossanitários se agravaram nos últimos anos, principalmente com relação a $S$. frugiperda que pode atacar a cultura de milho em qualquer época do ano (Cruz, 1995; Cruz et al., 1995). Consequentemente, o uso de inseticidas para o controle de pragas tem sido maior nesta cultura. A resistência de $S$. frugiperda ao piretróide lambda-cialotrina, um dos inseticidas mais utilizados para o seu controle, foi recentemente detectada em populações desta praga na cultura do milho no Brasil (Takaki et al., 1998). Uma rápida evolução da resistência de $S$. frugiperda a este inseticida (assim como para outros recomendados para o seu controle) era esperada devido à alta pressão seletiva a favor dos indivíduos resistentes em algumas regiões produtoras de milho.

O desenvolvimento da resistência de pragas a pesticidas é uma consequiência de sua utilização indiscriminada (Georghiou, 1983; Metcalf, 1983; Holloway, 1986). O estabelecimento de populações resistentes em um determinado ecossistema pode levar à aplicação mais freqüente de pesticidas, à utilização de dosagens mais elevadas, à adoção da prática de mistura e à mudança de produto, geralmente por um outro mais caro e tóxico (Georghiou, 1983). Estes fatores comprometem os programas de manejo integrado de pragas (MIP), em vista do aumento do custo de produção, da maior destruição de inimigos naturais e da maior contaminação do meio ambiente pelos pesticidas. O emprego de produtos alternativos, não afetados por resistência cruzada, tem sido uma importante ferramenta para combater a resistência. No entanto, a descoberta e o 
desenvolvimento de novos pesticidas estão se tornando cada vez mais dificil e oneroso (Metcalf, 1980, 1983; Hammock \& Soderlund, 1986; National Research Council, 1986). Além disso, a perda gradual na efetividade daqueles que ainda se encontram disponíveis no mercado, enfatizam a necessidade de implementação de estratégias de manejo da resistência de pragas a pesticidas, imprescindíveis para maximizar a vida útil dos mesmos (Georghiou, 1983).

A implementação de estratégias de manejo da resistência de pragas a pesticidas depende do conhecimento de parâmetros genéticos, biológicos e operacionais que influenciam no processo de evolução da resistência (Georghiou \& Taylor, 1977a, b). Dentre estes fatores, os genéticos têm recebido consideravelmente menor atenção que os outros (McKenzie, 1996). A determinação da herança da resistência e do valor adaptativo dos indivíduos resistentes em relação aos susceptíveis são importantes componentes para a elaboração e refinamento de programas de manejo da resistência (Roush \& Daly, 1990; Tabashnik, 1991; McKenzie, 2000). Estas informações auxiliam na deteç̧ão e monitoramento da resistência, na avaliação do potencial de risco de evolução e nos estudos de modelos de simulação (Tabashnik, 1991). De acordo com Roush \& Daly (1990), para um completo estudo da herança da resistência são necessários avaliar o número de genes envolvidos, as relações de dominância $\mathrm{e}$ as bases genéticas da resistência cruzada entre os diversos inseticidas.

Para uma melhor compreensão da resistência de $S$. frugiperda a lambdacialotrina em condições de Brasil, os objetivos deste estudo foram o de caracterizar a genética da resistência e avaliar o custo adaptativo dos indivíduos resistentes com relação a alguns parâmetros biológicos; fornecendo assim bases para a elaboração de um programa de manejo da resistência de $S$. frugiperda ao citado inseticida. 


\section{REVISÃO DE LITERATURA}

\subsection{Resistência de Spodoptera frugiperda a inseticidas}

O primeiro relato de resistência de $S$. frugiperda a um inseticida foi reportado por Young \& McMillian (1979) para populações coletadas em milho, no estado da Geórgia nos Estados Unidos. As lagartas foram classificadas como resistentes ou susceptiveis, de acordo com a sua capacidade de detectar as superficies tratadas com carbaril. A mortalidade na superficie tratada foi de $58 \%$ para a linhagem susceptivel, significativamente diferente da linhagem resistente que foi de $19 \%$, evidenciando que mecanismos comportamentais e fisiológicos estariam associados à resistência de $S$. frugiperda ao carbaril.

A susceptibilidade de $S$. frugiperda a inseticidas em função da idade larval foi estudado por $\mathrm{Yu}$ (1983). $\mathrm{O}$ autor constatou um incremento na $\mathrm{DL}_{50}$ com a idade. $\mathrm{O} 6^{\circ}$ ínstar foi 135,154 e 236 vezes mais tolerante que o $3^{\circ}$ ínstar aos inseticidas metomil, diazinon e permetrina, respectivamente. Foi observado também um aumento na toxicidade para os três inseticidas quando o sinergista butóxido de piperonila foi adicionado, porém sem evidências de diminuição na penetração cuticular.

Em estudos desenvolvidos por McCord \& Yu (1987) sobre os mecanismos da resistência de $S$. frugiperda ao carbaril, o emprego de butóxido de piperonila permitiu reduzir a intensidade da resistência de 90 para 6 vezes. Sendo assim, a destoxificação através das monoxigenases dependentes do citocromo P-450 foi considerada como o principal mecanismo de resistência de $S$. frugiperda ao carbaril. 
A intensidade da resistência de $S$. frugiperda aos inseticidas usualmente utilizados no seu controle foi estudada por Yu (1991) em populações coletadas na cultura de milho na Flórida, Estados Unidos. A intensidade de resistência para inseticidas piretróides variou de 2 a 216 vezes, para organofosforados de 121 a 271 vezes e para carbamatos de 14 a $>192$ vezes. As maiores intensidades foram encontradas para os inseticidas fluvalinato, paration metil e carbaril. A intensidade de resistência para o inseticida lambda-cialotrina foi de 12,5 vezes. Posteriormente, estudos bioquímicos realizados por $\mathrm{Yu}$ (1992) indicaram que o amplo espectro de resistência de $S$. frugiperda foi devido a múltiplos mecanismos, incluindo o incremento na destoxificação e a insensibilidade do sítio de ação dos inseticidas.

No Brasil, Takaki et al. (1998) detectaram diferenças significativas na susceptibilidade à lambda-cialotrina em populações de $S$. frugiperda provenientes de três regiões produtoras de milho (Guaíra, SP; Rio Verde, GO e Cascavel, PR). A porcentagem de sobreviventes na concentração diagnóstica de 32 ppm de lambdacialotrina, através de bioensaios de aplicação tópica, variou de 3 a $40 \%$; evidenciando assim uma grande variabilidade na resposta de populações de $S$. frugiperda a esse inseticida.

\subsection{Genética da resistência de lepidópteros a pesticidas}

O desenvolvimento da resistência de pragas a pesticidas é um processo evolucionário resultante da pressão de seleção. Sendo assim, estudos para determinar as bases genéticas da resistência e o custo adaptativo dos indivíduos resistentes em relação aos susceptíveis, são essenciais para uma melhor compreensão da evolução da resistência e posterior elaboração e refinamento de estratégias de manejo (Roush \& Daly, 1990; Tabashnik, 1991; McKenzie, 2000).

Estudos de herança da resistência geralmente envolvem cruzamentos reciprocos entre linhagens susceptiveis e resistentes e retrocruzamentos entre a progênie $F_{1}$ (heterozigotos) e a geração parental (susceptivel ou resistente) para determinar a 
dominância e o número de genes, respectivamente (Uyenoyama, 1986; Roush \& Daly, 1990; Tabashnik, 1991; McKenzie, 2000). O grau de dominância é definido através do fenótipo da geração $F_{1}$ com relação à susceptibilidade a um determinado pesticida (McKenzie, 1996).

Sabendo-se que a evolução da resistência só ocorre através da discriminação entre os genótipos em uma população, os indivíduos heterozigotos são considerados os mais importantes por carregar o alelo resistente com maior freqüência no início do processo de desenvolvimento da resistência (Roush \& McKenzie, 1987). Sendo assim, um dos princípios para o manejo da resistência consiste no controle de heterozigotos (Roush, 1989).

Em algumas situações, a dominância da resistência é uma caracteristica relativa à dosagem do produto. Deste modo, quando a herança da resistência é intermediária, com a aplicação de uma dosagem suficientemente alta para matar os individuos heterozigotos, a resistência é tida como funcionalmente recessiva (Tabashnik \& Croft, 1982; Georghiou \& Taylor, 1986; Roush \& Daly, 1990). Teoricamente, a evolução da resistência pode ser retardada nessas condições (Georghiou \& Taylor, 1977b; Futuyma, 1993). Porém, o emprego de altas dosagens de qualquer produto é considerada econômica e ecologicamente inviável e a dosagem a ser utilizada é de difícil identificação até que a resistência atinja uma freqüência relativamente elevada (Leeper et al., 1986). O sucesso da estratégia de altas dosagens depende também da migração de indivíduos susceptiveis. Contrariamente, através da aplicação de baixas dosagens, os heterozigotos podem sobreviver fazendo com que a resistência seja funcionalmente dominante, estratégia esta que pode acelerar o seu desenvolvimento em alguns casos (Tabashnik \& Croft, 1982; Georghiou \& Taylor, 1986). Segundo Roush (1989), o manejo da resistência através da alteração na dosagem do produto é bastante discutivel.

A evolução da resistência de pragas a pesticidas em agroecossistemas é geralmente controlada por um ou poucos genes (Brattsten et al., 1986; Plapp Jr., 1986; Roush \& McKenzie, 1987), ao contrário do que acontece nos estudos de seleção para 
resistência em laboratório, onde esta tende a ser poligênica devido a uma discriminação mais precisa entre genótipos (Roush \& McKenzie, 1987).

A maioria dos trabalhos têm revelado que a resistência de importância prática segue o modelo de herança monogênica (McDonald \& Schmidt, 1987; Daly \& Fisk, 1992, 1993; Yu, 1993; Yu \& Nguyem, 1994; Tang et al., 1997). Porém, existem estudos documentando a ocorrência de herança poligênica (Tabashnik \& Cushing, 1989). Plapp Jr. et al. (1979) mostraram que a resistência poligênica evolui mais lentamente quando comparada à monogênica.

A herança da resistência de Heliothis virescens (F.) ao paration metil foi estudada por Whitten (1978) através de cruzamentos entre linhagens susceptível e resistente, concluindo que a resistência é controlada por um gene principal, autossomal e de dominância incompleta. Os resultados sugeriram a presença de genes secundários conferindo a resistência. Por outro lado, Payne et al. (1988) demonstraram que a resistência de $H$. virescens à permetrina foi incompletamente recessiva e autossomal, controlada por um gene principal e também sob a influência de genes secundários. Para cipermetrina, a resistência de $H$. virescens foi intermediária e com um possível efeito maternal (Elzen at al., 1994).

Daly \& Fisk (1992, 1993) determinaram que a resistência de Helicoverpa armigera (Hübner) ao fenvarelate foi incompletamente dominante e monogênica. Neste caso, o principal mecanismo de resistência foi um aumento na destoxificação metabólica do inseticida através das monoxigenases dependentes do citocromo P-450. Por outro lado, Tan \& McCaffery (1999) observaram que a herança da resistência desta praga através da alteração no alvo de ação para DDT e fenvalerate parece ser controlada por um gene incompletamente recessivo.

A herança da resistência de Pectinophora gossypiella (Saunders) à permetrina foi incompletamente dominante e monogênica, com contribuição de fatores adicionais (Osman et al., 1992).

Tabashnik et al. (1992) testaram a descendência de vários cruzamentos de Plutella xylostella (L.) para estudar a herança da resistência a Bacillus thuringiensis. Os 
resultados obtidos evidenciaram que este caráter foi recessivo, autossomal e controlado por um ou poucos loci.

Yu (1993) demonstrou que a resistência de $P$. xylostella à permetrina foi incompletamente recessiva, enquanto que a resistência ao metomil foi incompletamente dominante. Para os dois inseticidas, a herança foi controlada por fatores autossômicos e a resistência foi associada ao aumento na destoxificação através das monoxigenases dependentes do citocromo P-450.

Yu \& Nguyen (1994) estudaram a herança da resistência a carbaril em $S$. frugiperda, através de cruzamentos e retrocruzamentos com o parental susceptível. A resistência foi determinada como incompletamente dominante e controlada por um gene autossomal; devida ao aumento da atividade das monoxigenases dependentes do citocromo P-450.

Através dos trabalhos levantados, verifica-se que a herança da resistência a piretróides em particular, não apresenta um padrão para lepidópteros, possivelmente devido à existência de diferentes mecanismos de resistência nas linhagens estudadas e suas possiveis interações (Yu, 1993; Tan \& McCaffery, 1999).

\subsection{Custo adaptativo da resistência de pragas a pesticidas}

A diminuição da freqüência de resistência a um determinado pesticida na ausência de pressão seletiva é uma das premissas básicas para a implementação de algumas estratégias de manejo da resistência, principalmente a rotação de produtos (Georghiou, 1983; National Research Council, 1986; Sawicki, 1987; Dennehy et al., 1990). Os fatores que contribuem na diminuição da freqüência podem estar ligados ao custo adaptativo dos indivíduos resistentes em relação aos susceptíveis e à possibilidade de migração de susceptíveis de áreas não tratadas (ou de plantas hospedeiras alternativas) para as tratadas (Georghiou, 1983; Roush \& McKenzie, 1987; Roush \& Daly, 1990).

Sabe-se que os indivíduos resistentes são menos adaptados do que os susceptíveis na ausência de pressão seletiva, caso contrário os alelos que conferem 
resistência seriam os predominantes mesmo antes do início da utilização de um determinado pesticida (Crow, 1957; Georghiou, 1983). No entanto, a resistência nem sempre aparece associada a desvantagens reprodutivas, e as diferenças entre as linhagens susceptível e resistente podem ser insignificantes ou esta última apresenta algumas vantagens (Varzandeh et al., 1954; Perkins Jr. \& Grayson, 1961; Thomas \& Brazzel, 1961; Roush \& Hoy, 1981). Nas linhagens resistentes largamente estabelecidas no laboratório e submetidas a uma contínua pressão de seleção, essas desvantagens podem ser subestimadas devido à coadaptação (Georghiou \& Taylor, 1986; Roush \& Croft, 1986; Uyenoyama, 1986). Porém, McKenzie (1996) considera que a coadaptação ocorre apenas em baixas proporções.

Retrocruzamentos são comumente utilizados para estudar as desvantagens no valor adaptativo associadas com resistência (Roush \& McKenzie, 1987; Roush \& Daly, 1990). Para isolar o(s) gene(s) resistente(s) dos genes modificadores, nos casos onde a resistência é um caráter dominante, são realizados cruzamentos entre as linhagens susceptivel e resistente para a obtenção da linhagem heterozigota, e posterior retrocruzamento desta linhagem com o parental susceptível para permitir a incorporação do gene que confere a resistência dentro do genoma susceptível. Este procedimento deve ser realizado no mínimo por três gerações para a obtenção de uma linhagem isogênica (Roush \& Daly, 1990).

Mesmo quando as diferenças no valor adaptativo entre os genótipos susceptivel e resistente são observadas, é mais relevante avaliar se essas diferenças também ocorrem entre os individuos susceptíveis e heterozigotos, pois sabe-se que durante a etapa inicial de desenvolvimento da resistência e de reversão para susceptibilidade, a maior freqüência de alelos resistentes é carregada pelos heterozigotos (Roush \& Croft, 1986). Roush \& Plapp Jr. (1982) enfatizaram a importância de se avaliar o potencial reprodutivo dos heterozigotos, particularmente quando a resistência é dominante, já que estes indivíduos apresentariam o fenótipo resistente.

Para reduzir o valor adaptativo dos indivíduos resistentes em programas de manejo da resistência, Roush \& Daly (1990) sugerem o emprego de altas dosagens, 
sinergistas, misturas e de pesticidas que conferem baixas intensidades de resistência, assim como a aplicação do produto no estágio mais vulnerável da praga.

Estudos para determinar a influência da resistência a inseticidas clorados e piretrinas no potencial biótico de Musca domestica L. foram desenvolvidos por Varzandeh et al. (1954). Os dados obtidos mostraram que a herança de fatores associados ao valor adaptativo foram independentes daqueles relacionados à resistência. As diferenças no potencial biótico entre as linhagens resistentes e susceptíveis não foram significativas.

O efeito da resistência de $M$. domestica a inseticidas organofosforados sobre o valor adaptativo foi estimado por Roush \& Plapp Jr. (1982). Neste estudo, a linhagem resistente mostrou uma diminuição de 11 a $43 \%$ no potencial biótico quando comparada com a linhagem susceptível. $\mathrm{O}$ custo adaptativo foi associado à redução na fertilidade $\mathrm{e}$ incremento no tempo de desenvolvimento. Em contraste, os individuos heterozigotos (resistentes) se comportaram como o parental susceptivel, concluindo que o gene da resistência foi dominante para expressar resistência e recessivo para os efeitos adversos no valor adaptativo.

Ferrari \& Georghiou (1981) determinaram a influência do temefós sobre o potencial reprodutivo de Culex quinquefasciatus Say em linhagens resistente, susceptível e heterozigota. A linhagem resistente apresentou menor fecundidade e viabilidade e um maior tempo de desenvolvimento do que a susceptível. Entretanto, os indivíduos heterozigotos não apresentaram nenhum custo adaptativo. Um trabalho similar foi efetuado por El-Khatib \& Georghiou (1985), onde a redução na eclosão de larvas de $C$. quinquefasciatus foi associada à resistência ao temefós sob a influência de fatores maternais. As taxas de desenvolvimento larval e sobrevivência foram significativamente menores na linhagem resistente e relacionada ao genótipo do macho. O periodo pupal e a emergência de adultos foram maiores na linhagem resistente.

Uma linhagem isogênica foi obtida por Amin \& White (1984) para avaliar o valor adaptativo da resistência de $C$. quinquefasciatus ao clorpirifós. Para tanto, os autores realizaram cruzamentos entre machos resistentes e fềmeas susceptiveis e 
retrocruzaram a progênie resultante por estas últimas durante cinco gerações. Os resultados obtidos revelaram um baixo valor adaptativo da linhagem resistente. Entretanto, os resultados dos parâmetros biológicos avaliados para a linhagem isogênica foram semelhantes aos da linhagem susceptivel; indicando que as diferenças entre as três linhagens estariam ligadas principalmente a outros fatores genômicos e não ao gene que confere a resistência. O longo período de colonização da linhagem susceptivel no laboratório poderia ter contribuído para sua melhor adaptação.

Para estudar o custo do valor adaptativo de Leptinotarsa decemlineata (Say) ao azinfós metil e permetrina, Argentine et al. (1989) criaram linhagens isogênicas através do retrocruzamento da linhagem resistente com a linhagem susceptível por um periodo de quatro gerações. Os indivíduos heterozigotos foram obtidos através do cruzamento de machos susceptiveis por fềmeas resistentes a cada inseticida. A linhagem susceptivel produziu um maior número de ovos e larvas que a resistente a azinfós metil (não isogênica), entretanto a linhagem resistente levou 3,5 dias a mais para se desenvolver. Estes fatores levaram a uma redução no valor adaptativo, o que pode ter sido ocasionado por alelos resistentes ou por outras diferenças genômicas não relacionadas com a resistência. A produção de ovos e larvas foi menor na linhagem isogênica do que na susceptível, o tempo de desenvolvimento foi maior em 1,5 dias e o número de fềmeas adultas produzidas foi a metade da susceptivel. Apesar destas diferenças não serem tão expressivas como na linhagem resistente, estes valores foram significativos. Para os heterozigotos, não se registraram grandes diferenças nestes parâmetros quando comparados com a linhagem susceptivel. Foi observado também que o alelo conferindo resistência à permetrina não causou desvantagens no valor adaptativo do inseto.

Alyokhin \& Ferro (1999) comprovaram que uma linhagem de L. decemlineata resistente a $B$. thuringiensis apresentou um baixo valor adaptativo na ausência de pressão de seleção. Neste caso, a preservação de refúgios para individuos susceptiveis e a rotação de produtos permitiria diminuir a freqüência do alelo resistente. Por outro lado, Tang et al. (1997) não detectaram redução no valor adaptativo de linhagens de $P$. xylostella resistentes a $B$. thuringiensis. 
Foster et al. (1999) observaram que a redução na resposta ao feromônio de alarme no pulgão Myzus persicae (Sulzer), estaria relacionada com resistência a inseticidas do tipo "kdr" (resistência do tipo "knock-down"). Isto determinaria um custo no valor adaptativo através de um aumento na vulnerabilidade a inimigos naturais na ausência de pressão seletiva.

Linhagens resistentes e susceptiveis de Trialeurodes vaporariorum Westwood a acefato e dicrotofós foram comparadas por Omer et al. (1992). Os indivíduos resistentes apresentaram uma maior fecundidade e uma longevidade maior ou igual aos individuos susceptiveis. Estes resultados sugerem que o valor adaptativo dos indivíduos resistentes poderia favorecer a estabilidade da resistência de $T$. vaporariorum a estes inseticidas.

Campanhola et al. (1991) enfatizaram a escassez de trabalhos avaliando diferenças biológicas entre linhagens susceptíveis e resistentes em lepidópteros. Estes mesmos autores conduziram testes para explicar a instabilidade da resistência a piretróides em $H$. virescens, tanto no campo como no laboratório na ausência de pressão de seleção. As fềmeas resistentes apresentaram uma menor fertilidade e menor produção de feromônio, e consequentemente atraíram um menor número de indivíduos machos. As fềmeas susceptíveis, se acasalaram mais freqüentemente e os machos foram mais atraídos por armadilhas de feromônio. Estes dados comprovaram que a resistência de $H$. virescens a piretróides está associada a um custo adaptativo.

Glenn et al. (1994) determinaram que a resistência ao fenvalerate não estaria relacionada com efeitos deletérios em $H$. armigera, pois as linhagens resistentes se multiplicaram tão bem quanto a susceptível em laboratório, sugerindo que provavelmente o custo da resistência possa estar ligado a outros parâmetros biológicos não avaliados no trabalho. 


\subsection{Biologia de Spodoptera frugiperda em dietas artificiais}

A avaliação do custo adaptativo da resistência de pragas a pesticidas tem sido tradicionalmente realizada através da comparação de parâmetros biológicos tais como fecundidade, fertilidade, tempo para desenvolvimento e competição para acasalamento de cada genótipo, ou então através do acompanhamento da freqüência de resistência em diversas populações no decorrer do tempo (Roush \& McKenzie, 1987). Diversos são os trabalhos reportados com relação a parâmetros biológicos de $S$. frugiperda quando criada em dietas artificiais.

Estudos para determinar o efeito de folhas de sorgo e dieta artificial à base de germe-de-trigo e caseína sobre o desenvolvimento de $S$. frugiperda foram conduzidos por Bailey \& Chada (1968). O ciclo de vida obtido em cada substrato foi de 35 e 35,6 dias, respectivamente. A média de ovos produzidos por fềmea foi de 849 na dieta natural e de 868 na dieta artificial. Para as duas dietas, as durações das fases de ovo, larva, pupa e adulto foram de aproximadamente $3 ; 10 ; 15$ e 7,5 dias, respectivamente.

Visando diminuir o preço e o tempo gasto na preparação de dietas artificiais para a criação de $S$. frugiperda, Burton \& Perkins (1972) testaram uma dieta artificial à base de germe-de-trigo e soja. Foi constatada uma média de 1901 ovos por fềmea, apresentando uma viabilidade de $88,4 \%$. A duração média do período pupal foi de 13,5 dias.

Kasten Jr. et al. (1978) estudaram a biologia de $S$. frugiperda em dieta artificial à base de feijão e germe-de-trigo comparada com substrato natural (milho). Para a fase de ovo, a viabilidade foi de $54,5 \%$ na dieta à base de germe-de-trigo e a duração e viabilidade da fase larval foram de 16,8 dias e $57,5 \%$, respectivamente. Para a fase pupal, a duração foi de 8 dias e a viabilidade de $58,7 \%$. O peso de pupas foi maior para fềmeas em todos os substratos avaliados, sendo que na dieta contendo germe-de-trigo, o peso foi de $233 \mathrm{mg}$ para machos e $237 \mathrm{mg}$ para fềmeas. $\mathrm{Na}$ fase adulta foi registrado um número médio de ovos por fềmea de 703,6. A longevidade dos indivíduos foi de 7,4 dias para 
machos e 7,5 dias para fềmeas. A razão sexual foi de 0,50 e o ciclo total de 30,9 dias na dieta à base de germe-de-trigo.

Pencoe \& Martin (1981) estudaram o desenvolvimento e fecundidade de $S$. frugiperda sobre plantas hospedeiras e dieta artificial à base de feijão. Foram observados uma menor duração da fase larval (16,7 dias), menor número de ínstares (6) e maior peso pupal $(265,3 \mathrm{mg})$ em dieta artificial.

Ferraz (1982) trabalhou com dieta artificial à base de feijão em 4 temperaturas constantes $\left(20 ; 25 ; 30\right.$ e $\left.35^{\circ} \mathrm{C}\right)$, observando que a viabilidade da fase de ovo foi decrescendo com a elevação térmica, sendo de $81,2 \%$ à temperatura de $25^{\circ} \mathrm{C}$. A duração da fase larval foi de 19,7 dias e a viabilidade de $72,5 \%$ nesta temperatura, observando-se um alongamento do periodo com o decréscimo da temperatura. A duração da fase pupal diminuiu com o aumento da temperatura, sendo a $25^{\circ} \mathrm{C}$ de 9,3 dias para ambos os sexos, com uma viabilidade de $100 \%$. O peso médio de pupas foi de $170 \mathrm{mg}$ para machos e 160 mg para fềmeas e a razão sexual de 0,53. A longevidade de adultos foi decrescente com a elevação térmica, e em todas as temperaturas os machos apresentaram uma maior longevidade do que as fềmeas. Na temperatura de $25^{\circ} \mathrm{C}$, a longevidade foi de 12,4 dias para machos e de 11,1 dias para fêmeas e o número médio de ovos colocados por fềmea foi de 1269. O ciclo de vida total (ovo-adulto) foi de 46,5 dias.

Parra \& Carvalho (1984) compararam a biologia de $S$. frugiperda em meios artificiais compostos de diferentes variedades de feijão; resultando ser mais promissora a variedade Carioca por proporcionar uma menor duração do ciclo total (ovo-adulto) que foi de 31,5 dias e uma maior viabilidade total $(63,7 \%)$ em relação às demais. Para as fases de larva e pupa, a duração foi de 20,5 e 9 dias; e a viabilidade de 95,7 e 66,5\%, respectivamente. $O$ peso médio das pupas foi de $238,2 \mathrm{mg}$.

$O$ efeito do germe-de-trigo e vitaminas foi estudado por Mielitz et al. (1986), observando uma redução na duração da fase larval (19,5 dias) quando o primeiro foi adicionado à dieta. A duração e o peso de pupas foi de 13,9 dias e 260,2 mg para machos e de 12,8 dias e $275,9 \mathrm{mg}$ para fềmeas. A duração do período de eclosão das lagartas à emergência de adultos foi de 34,7 dias. 
Nalim (1991) conduziu estudos biológicos de $S$. frugiperda em duas dietas artificiais, uma à base de levedura de cerveja e feijão e outra contendo levedura de cerveja, germe-de-trigo e feijão como fontes protéicas. Nesta última, a duração da fase larval foi de 17,3 dias e a viabilidade de $98,3 \%$ a $25 \pm 2^{\circ} \mathrm{C}$. A duração da fase pupal foi de 11 dias com uma viabilidade de $96 \%$ e razão sexual de 0,48 . O peso médio das mesmas foi de $270 \mathrm{mg}$. No periodo adulto, a longevidade dos indivíduos foi de 15,8 dias e o total de ovos por fềmea de 2174. Para a fase de ovo, a viabilidade observada foi de $86,2 \%$. O ciclo total (ovo-adulto) foi de 33,2 dias, com uma viabilidade de $75 \%$ na dieta contendo germe-de-trigo, sendo considerada a mais adequada para a criação do inseto.

Seong $\mathrm{Ng}$ et al. (1993) estudaram a biologia de $S$. frugiperda criada sobre dieta à base de germe-de-trigo e caseína à temperatura de $26,7^{\circ} \mathrm{C}$, observando uma duração da fase larval de 14 dias para ambos os sexos e uma duração da fase pupal de 9,6 e 8,7 dias para machos e fềmeas, respectivamente. A duração desde a eclosão da lagarta até a emergência do adulto foi de 23,8 dias para machos e de 22,7 dias para fềmeas. 


\section{MATERIAL E MÉTODOS}

O trabalho foi desenvolvido no Laboratório de Resistência de Artrópodos a Pesticidas do Departamento de Entomologia, Fitopatologia e Zoologia Agrícola da Escola Superior de Agricultura "Luiz de Queiroz", Universidade de São Paulo, Piracicaba, SP, no periodo de março de 1998 a maio de 2000.

Uma população de laboratório de Spodoptera frugiperda, obtida através da EMBRAPA de Sete Lagoas, MG em 1995, foi considerada como a linhagem susceptível de referência (S). Esta população vinha sendo mantida em dieta artificial na ausência de pressão seletiva com inseticidas por pelo menos 5 anos.

A partir de um levantamento da susceptibilidade a inseticidas realizado em diversas populações de $S$. frugiperda coletadas nas principais regiões produtoras de milho no Brasil na safra de 1997/1998, uma população proveniente de Guaíra, SP foi selecionada para a caracterização da resistência à lambda-cialotrina. Esta população foi identificada como GUA, nome que corresponde às três primeiras letras do local onde foi efetuada a coleta. A linhagem resistente (R) de $S$. frugiperda à lambda-cialotrina foi obtida através de vários ciclos de seleção da população GUA com o referido inseticida em condições laboratoriais (ver item 3.3). 


\subsection{Criação de Spodoptera frugiperda em laboratório}

\subsubsection{Criação para a manutenção das populações}

As populações de $S$. frugiperda foram mantidas no laboratório em dieta artificial modificada de Perkins et al. (1973) à base de feijão, levedura de cerveja e germede-trigo (Tabela 1). Para a manutenção de cada população, lagartas de $1^{\circ}$ ínstar foram inoculadas em 200 tubos de vidro $(2,5 \mathrm{~cm}$ de diâmetro por $8 \mathrm{~cm}$ de altura) contendo dieta artificial (2 lagartas/tubo). Os procedimentos gerais para a criação foram realizados de acordo com as recomendações apresentadas por Parra (1996). A sala de criação foi mantida à temperatura de $25 \pm 2{ }^{\circ} \mathrm{C}$, umidade relativa de $70 \pm 10 \%$ e fotofase de 14 horas.

Tabela 1. Composição da dieta artificial utilizada para criação de $S$. frugiperda em laboratório (modificada de Perkins et al., 1973).

\section{Componentes}

Quantidade

\begin{tabular}{lc}
\hline ágar & $25,50 \mathrm{~g}$ \\
feijão (variedade Carioca) & $165,00 \mathrm{~g}$ \\
germe-de-trigo & $79,20 \mathrm{~g}$ \\
levedura-de-cerveja & $50,50 \mathrm{~g}$ \\
ácido ascórbico & $5,10 \mathrm{~g}$ \\
ácido sórbico & $1,65 \mathrm{~g}$ \\
metil-p-hidroxibenzoato (nipagin) & $3,15 \mathrm{~g}$ \\
água & $1195,00 \mathrm{ml}$ \\
formaldeído $10 \%$ & $12,50 \mathrm{ml}$ \\
\hline
\end{tabular}

Obs.: quantidade suficiente para 100 tubos de dieta 
As pupas foram retiradas dos tubos de vidro com o auxilio de uma espátula de metal e transferidas para placas de Petri $(10 \mathrm{~cm}$ de diâmetro por $1,5 \mathrm{~cm}$ de altura) contendo vermiculita, e cobertas posteriormente com um copo de plástico transparente. Após a emergência, os adultos foram transferidos para gaiolas cilíndricas de PVC $(10 \mathrm{~cm}$ de diâmetro por $20 \mathrm{~cm}$ de altura) revestidas internamente com papel jornal e fechadas nas extremidades superior e inferior com placas de Petri de $12,5 \mathrm{~cm}$ de diâmetro. Foram mantidos aproximadamente 10 casais por gaiola. $\mathrm{O}$ alimento foi fornecido por capilaridade através de um rolo dental de algodão, colocado em frascos de $10 \mathrm{ml}$, contendo solução de mel na concentração de $10 \%$. A solução foi renovada a intervalos de dois dias, evitando-se assim problemas de contaminação e fermentação.

As posturas obtidas no papel de revestimento das gaiolas foram recortadas e colocadas em placas de Petri de $10 \mathrm{~cm}$ de diâmetro por $1,5 \mathrm{~cm}$ de altura, junto com um pedaço de papel de filtro umedecido com água destilada e fechadas com uma tampa de igual tamanho através de fita adesiva. As placas contendo as massas de ovos foram devidamente identificadas e mantidas em câmara climatizada (marca FANEM, modelo $347 \mathrm{CDG}$ ) regulada à temperatura de $21 \pm 1^{\circ} \mathrm{C}$ e fotofase de 14 horas, até a eclosão das lagartas.

\subsubsection{Criação para bioensaios}

S. frugiperda apresenta hábito canibalístico, principalmente a partir do $3^{\circ}$ instar. Sendo assim, os testes toxicológicos foram realizados com lagartas de $3^{\circ}$ ínstar criadas em recipientes plásticos transparentes de $100 \mathrm{ml}$ com tampa. Para tanto, uma camada de aproximadamente $1 \mathrm{~cm}$ de dieta artificial foi colocada no fundo do recipiente onde posteriormente foram inoculadas lagartas recém eclodidas em uma densidade de 150 a 200 por recipiente. Os recipientes foram mantidos em uma sala de criação regulada à temperatura de $25 \pm 1{ }^{\circ} \mathrm{C}$, umidade relativa de $70 \pm 10 \%$ e fotofase de $14 \mathrm{~h}$, até que as lagartas atingissem o ínstar desejado para os bioensaios. 


\subsection{Procedimentos de bioensaio}

Para a realização dos bioensaios foi utilizada a técnica de aplicação tópica, que consistiu no tratamento de lagartas de $3^{\circ}$ instar com $1 \mu \mathrm{l}$ de solução do inseticida técnico lambda-cialotrina (pureza de 87,39\%, Zeneca Brasil Ltda.) diluído em acetona. As lagartas do tratamento testemunha receberam somente acetona. A aplicação foi realizada na região protorácica com o auxilio de um microaplicador automático (Burkard Manufacturing Company Ltd., Rickmansworth, Reino Unido), de acordo com a metodologia descrita por Yu (1983). Após a aplicação, as lagartas foram transferidas para recipientes descartáveis (100 ml de capacidade) contendo dieta artificial e mantidas em câmara climatizada regulada à temperatura de $25 \pm 1^{\circ} \mathrm{C}$ e fotofase de $14 \mathrm{~h}$. Em cada recipiente foram acondicionadas 5 lagartas. A mortalidade foi avaliada $24 \mathrm{~h}$ após a aplicação do inseticida.

\subsection{Caracterização da resistência de Spodoptera frugiperda à lambda-cialotrina}

Para a caracterização da linha-básica de susceptibilidade, seis concentrações de lambda-cialotrina espaçadas logaritmicamente entre 1 a $56 \mu \mathrm{g}$ de lambda-cialotrina / $\mathrm{ml}$ de acetona [ppm (I.A.)] foram testadas para a linhagem $\mathrm{S}$.

$\mathrm{Na}$ tentativa de isolar lagartas de S. frugiperda resistentes à lambda-cialotrina, a população GUA foi submetida a vários ciclos de seleção, utilizando-se inicialmente a $\mathrm{CL}_{95}$ da linhagem $\mathrm{S}$. Os indivíduos sobreviventes a cada seleção foram separados e colonizados, sendo a concentração do produto aumentada a cada ciclo. Após 6 ciclos de seleção a população obtida foi considerada resistente (linhagem R) à lambda-cialotrina. A curva de concentração-resposta foi caracterizada com sete concentrações entre 10 a 1000 ppm (I.A.).

Os dados de mortalidade das linhagens GUA, S e R foram submetidos à análise de próbite através do programa POLO-PC (LeOra Software, 1987). A razão de resistência (RR) foi estimada através da fórmula: 


$$
R R=\frac{C L_{s 0} \text { da linhagem } R}{C L \text { soda linhagem } S}
$$

\subsection{Herança da resistência de Spodoptera frugiperda à lambda-cialotrina}

Para o estudo da herança da resistência de $S$. frugiperda à lambda-cialotrina, foram utilizadas a população susceptivel de referência (linhagem $S$ ) e a população resistente selecionada (linhagem R). Pupas provenientes de cada população foram sexadas e mantidas separadamente em placas de Petri contendo vermiculita e tampadas com um copo de plástico transparente. À medida que os adultos foram emergindo, cruzamentos recíprocos entre dez casais $\left(\mathrm{R} \uparrow \times \mathrm{Xo}^{\pi}\right.$ e $\left.\mathrm{S} \uparrow \times \mathrm{Ro}^{\pi}\right)$ foram realizados nas gaiolas para acasalamento.

As progênies dos cruzamentos recíprocos foram submetidas aos bioensaios para a caracterização das curvas de concentração-mortalidade para lambda-cialotrina e posterior estimativa das $\mathrm{CL}_{50}$ s. Sabendo-se que a determinação do sexo nos lepidópteros é do tipo $\mathrm{ZW}$, onde as fềmeas são heterogaméticas e os machos homogaméticos; a possibilidade da resistência estar ligada ao sexo ou apresentar efeitos maternais foi verificada através da análise dos resultados obtidos nos cruzamentos recíprocos. Se as respostas à lambda-cialotrina para as progênies $F_{1}$ forem diferentes, a resistência poderia estar ligada ao sexo ou sob efeito maternal. Caso contrário, a resistência é considerada autossômica.

O grau médio de dominância da resistência foi estimado através da comparação das $\mathrm{CL}_{50} \mathrm{~S}$ das progênies $\mathrm{F}_{1}$ em relação as populações parentais, seguindo as recomendações apresentadas por Stone (1968), partindo-se da fórmula:

$$
\mathrm{D}=\frac{2 X_{3}-X_{2}-X_{1}}{X_{2}-X_{1}}
$$


onde:

$$
\begin{aligned}
& \mathrm{D}=\text { grau médio de dominância } \\
& X_{1}=\log _{10}\left(\mathrm{CL}_{50}\right) \text { da linhagem } \mathrm{S} \\
& X_{2}=\log _{10}\left(\mathrm{CL}_{50}\right) \text { da linhagem } \mathrm{R} \\
& X_{3}=\log _{10}\left(\mathrm{CL}_{50}\right) \text { da linhagem híbrida } \mathrm{F}_{1}
\end{aligned}
$$

Quando o valor de $\mathrm{D}$ é -1 , a resistência é considerada completamente recessiva, se $\mathrm{D}$ é igual a 0 é intermediária ou codominante e se é igual a +1 é completamente dominante.

Para estimar o número de genes envolvidos na resistência, foram realizados retrocruzamentos da progênie $F_{1}$ com o parental apresentando o fenótipo mais distinto destes individuos (Tsukamoto, 1983; Roush \& Daly, 1990). Deste modo se o caráter resistência for dominante, a progênie $F_{1}$ é retrocruzada com o parental susceptivel (SS). Assim, quando a herança é monogênica, o resultado será $50 \%$ de indivíduos susceptíveis (SS) e $50 \%$ de indivíduos resistentes (RS). Por outro lado, se dois genes $\left(R_{1}\right.$ e $\left.R_{2}\right)$ estão envolvidos, e os parentais são homogêneos para ambos loci, os indivíduos $F_{1}$ serão todos $R_{1} S_{1} R_{2} S_{2}$. O retrocruzamento destes indivíduos com o parental susceptível $\left(S_{1} S_{1} S_{2} S_{2}\right)$, dará quatro diferentes genótipos em igual freqüência (assumindo que os genes não estão ligados no mesmo cromossomo): $\mathrm{S}_{1} \mathrm{~S}_{1} \mathrm{~S}_{2} \mathrm{~S}_{2}, \mathrm{~S}_{1} \mathrm{~S}_{1} \mathrm{R}_{2} \mathrm{~S}_{2}, \mathrm{R}_{1} \mathrm{~S}_{1} \mathrm{~S}_{2} \mathrm{~S}_{2}$ e $\mathrm{R}_{1} \mathrm{~S}_{1} \mathrm{R}_{2} \mathrm{~S}_{2}$. Se as contribuiç̃̃es dos alelos que conferem a resistência são iguais e aditivas, espera-se que a concentração que mata os indivíduos $\mathrm{S}_{1} \mathrm{~S}_{1} \mathrm{~S}_{2} \mathrm{~S}_{2}$ também mate parte dos indivíduos $S_{1} S_{1} R_{2} S_{2}$ e $R_{1} S_{1} S_{2} S_{2}$. Sendo assim, quando a resistência é poligênica, a mortalidade observada nos retrocruzamentos será significativamente superior a $50 \%$ (Roush \& Daly, 1990).

A possibilidade de herança monogênica foi testada através do teste do $\chi^{2}$ entre os dados de mortalidade observada e esperada do retrocruzamento de $F_{1}$ com um dos parentais. A mortalidade esperada do retrocruzamento a uma determinada concentração foi calculada como a soma da metade da mortalidade da progênie $F_{1}$ mais a metade da 
mortalidade da linhagem parental nesta mesma concentração (Preisler et al., 1990; Tabashnik, 1991; Tabashnik et al., 1992).

\subsection{Custo adaptativo da resistência de Spodoptera frugiperda à lambda-cialotrina}

Para verificar um possivel decréscimo na freqüência de resistência de $S$. frugiperda na ausência de pressão seletiva com lambda-cialotrina devido à presença de custo adaptativo da resistência, foram realizados estudos de biologia comparativa entre as linhagens $S$, isogênica-R e heterozigota $\left(F_{1}\right)$.

Para isolar o gene que confere resistência e eliminar outros que poderiam interferir na avaliação do custo adaptativo dos individuos resistentes, foi criada uma linhagem isogênica (isogênica- $R$ ), através de uma série de cruzamentos entre a linhagem S e R para a obtenção da geração heterozigota $\left(F_{1}\right)$, e seguidos de intercruzamentos desta progênie $\left(F_{1} \times F_{1}\right)$ para o isolamento de indivíduos resistentes homozigotos a serem retrocruzados com a linhagem S. Foi utilizado o bioensaio de aplicação tópica (descrito no item 3.2) à concentração de $32 \mu \mathrm{g}$ de lambda-cialotrina $/ \mathrm{ml}$ de acetona para o isolamento de indivíduos resistentes. Após 3 ciclos de retrocruzamentos e intercruzamentos, os sobreviventes através do bioensaio dos indivíduos resultantes do intercruzamento da geração heterozigota constituíram a linhagem isogênica-R.

Os parâmetros biológicos avaliados para cada linhagem foram os seguintes:

Fase de larva:

$$
\begin{aligned}
& \text {-duração } \\
& \text {-viabilidade }
\end{aligned}
$$

Fase de pupa:

$$
\begin{aligned}
& \text {-duração } \\
& \text {-viabilidade } \\
& \text {-razão sexual }
\end{aligned}
$$


-peso com 24 horas de idade

Fase adulta:

-longevidade

-fecundidade (número de ovos/fềmea)

-período de pré-oviposição

-periodo de oviposição

Fase de ovo:

-duração

-viabilidade

Ciclo total:

-duração do período

Os estudos foram iniciados com 200 lagartas de $1^{\circ}$ instar para cada uma das linhagens (susceptível, isogênica- $R$ e $F_{1}$ ) que foram inoculadas em tubos contendo dieta artificial (1 lagarta/tubo).

Após o acompanhamento da fase larval, as pupas foram retiradas dos tubos e pesadas com 24 horas de idade em balança eletrônica de precisão e separadas por sexo. A razão sexual (rs) foi determinada pela seguinte fórmula:

$$
\mathrm{rs}=\frac{q}{\sigma^{x}+q}
$$

Posteriormente, as pupas foram acondicionadas em bandejas plásticas revestidas com papel de filtro e tampadas individualmente com um copo de plástico (50 $\mathrm{ml}$ ). O papel de filtro foi diariamente umedecido com água destilada. As pupas foram 
conservadas em câmara climatizada a $25 \pm 1{ }^{\circ} \mathrm{C}$, umidade relativa de $70 \pm 10 \%$ e fotofase de $14 \mathrm{~h}$ até a emergência dos adultos.

Após a emergência, foram separados 20 casais da mesma idade por linhagem, para obter os dados referentes à fase adulta. Os casais foram mantidos em gaiolas de PVC, revestidas internamente por papel jornal o qual servia de substrato de postura.

Os ovos foram retirados e contados diariamente, procedendo-se primeiramente à contagem daqueles localizados na camada superior, multiplicados pelo número de camadas existentes na postura; adicionando-se os ovos contados nas bordas das camadas subseqüentes (Leuck \& Perkins, 1972).

Para a determinação da viabilidade de ovos e do período de incubação foi considerada a segunda postura por casal de cada população. De cada postura foram retirados, com o auxilio de um pincel fino sob microscópio estereoscópico, uma amostra contendo aproximadamente 200 ovos. Estes foram colocados em placas de Petri $10 \mathrm{~cm}$ de diâmetro por $1,5 \mathrm{~cm}$ de altura), contendo papel de filtro umedecido com água destilada. As placas foram tampadas com placas do mesmo diâmetro, vedadas com fita adesiva e conservadas em câmara climatizada a $25 \pm 1^{\circ} \mathrm{C}$, umidade relativa de $70 \pm 10 \%$ e fotofase de 14 horas. A eclosão das lagartas foi observada diariamente.

$O$ delineamento experimental utilizado foi inteiramente casualizado e cada repetição foi constituída de um grupo de 10 insetos. Para o parâmetro viabilidade, os dados de porcentagem $(P)$ foram previamente transformados para arco seno $\sqrt{P / 100}$ para a análise estatística. Para os parâmetros correspondentes à fase adulta, cada casal foi considerado como uma repetição e para longevidade, cada indivíduo. Os resultados foram submetidos à análise de variância e as médias de cada parâmetro avaliados separadamente através do teste de Tukey ao nível de $5 \%$ de probabilidade.

As razões sexuais de cada linhagem foram analisadas através do teste do quiquadrado.

Os dados biológicos das linhagens $\mathrm{S}$, isogênica- $\mathrm{R}$ e $\mathrm{F}_{1}$ foram também analisados através da elaboração de tabelas de vida de fertilidade, segundo Silveira Neto 
et al. (1976). Os parâmetros estimados foram a taxa líquida de reprodução $\left(R_{0}\right)$, a duração média de uma geração $(T)$, a capacidade inata de aumentar em número $\left(r_{m}\right)$ e a razão finita de aumento $(\lambda)$. Para a elaboração das tabelas de vida de fertilidade foram observados 20 casais de cada linhagem. Fêmeas que não colocaram ovos também foram computadas nos cálculos. 


\section{RESULTADOS E DISCUSSÃO}

\subsection{Caracterização da resistência de Spodoptera frugiperda à lambda-cialotrina}

Uma resposta significativa à pressão de seleção da população GUA com lambda-cialotrina foi observada após 6 ciclos de seleção para a obtenção da linhagem resistente (R) (Figura 1). Para a caracterização da população GUA, foram testados 925 indivíduos, sendo a $\mathrm{CL}_{50}$ de 23,31 ppm de lambda-cialotrina (IC 95\% 15,43-34,08), coeficiente angular ( \pm desvio padrão) de $0,97( \pm 0,11), \chi^{2}$ de 2,74 (graus de liberdade $=3$, $P>0,05$ ). Para a linhagem $\mathrm{R}$, foram testados 3602 individuos. $A \mathrm{CL}_{50}$ foi de $118,49 \mathrm{ppm}$ (IC 95\% 87,71-156,87), coeficiente angular ( \pm desvio padrão) de $1,62( \pm 0,06), \chi^{2}$ de 24,34 (graus de liberdade $=5, P>0,05$ ).

A resposta à seleção pode ser evidenciada através dos incrementos da $\mathrm{CL}_{50}$ (de aproximadamente 5 vezes) e do coeficiente angular para a linhagem $R$ com relação a esses dados para a população GUA. Sabe-se que quanto maior o coeficiente angular, maior a homogeneidade de uma população (Hoskins \& Gordon, 1956; Tsukamoto, 1983). A inclinação da linha de concentração-resposta pode também estar ligado ao método de bioensaio utilizado (ffrench-Constant \& Roush, 1990). Segundo McKenzie (2000), o coeficiente angular da análise dos dados toxicológicos revela o nível de variação fenotípica de uma população, sem indicar necessariamente uma variação genética ou influência do ambiente. Porém, como as duas populações foram testadas com o mesmo método de bioensaio, os resultados evidenciaram uma maior homogeneidade para a linhagem $R$, o que sugere um aumento na homozigosidade com a seleção. 


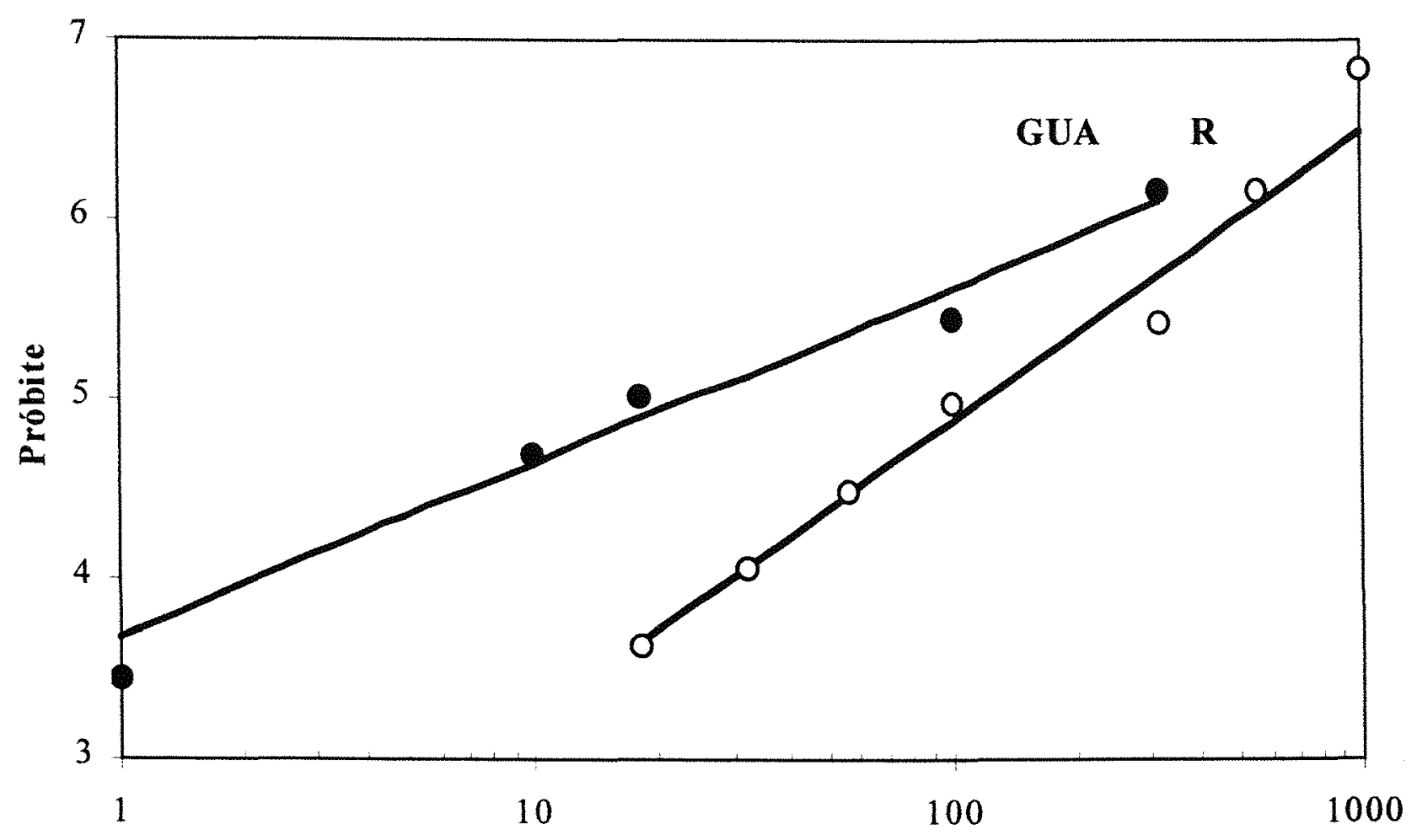

$\mu \mathrm{g}$ de lambda-cialotrina/ $\mathrm{ml}$ acetona

Figura 1. Curvas de concentração-resposta da população GUA de $S$. frugiperda e da linhagem resistente $(\mathrm{R})$ obtida após 6 ciclos de seleção da população GUA com lambda-cialotrina. 
Para a caracterização da resistência de $S$. frugiperda à lambda-cialotrina, a resposta da linhagem $\mathrm{R}$ foi contrastada com a da linhagem $\mathrm{S}$ (Figura 2). Para a linhagem $\mathrm{S}$, foram avaliados 2401 individuos, sendo a $\mathrm{CL}_{50}$ de $9,20 \mathrm{ppm}$ (IC 95\% 5,81-13,37), coeficiente angular ( \pm desvio padrão) de $1,35( \pm 0,07), \chi^{2}$ de 18,31 (graus de liberdade= $4, P>0,05$ ) (Figura 2). Baseada na $\mathrm{CL}_{50}$, a razão de resistência de $S$. frugiperda à lambdacialotrina foi de 12,9. Um valor bastante próximo (ou seja, de 12,5 vezes) foi reportado por Yu (1991) na caracterização da intensidade de resistência de $S$. frugiperda à lambdacialotrina na Flórida, Estados Unidos. Nesse trabalho, o autor apresentou também as intensidades de resistência de $S$. frugiperda a outros piretróides (permetrina, cipermetrina, fenveralate, tralometrina, bifentrina, tetrametrina e fluvalinate), que variaram de 2 a 216 vezes. Sendo assim, o resultado obtido no presente trabalho não pode ser extrapolado para outros piretróides recomendados para o controle de $S$. frugiperda no Brasil.

Segundo Roush \& Daly (1990), uma intensidade de resistência superior a 6 vezes poderia provocar falhas no controle de uma determinada praga no campo. Portanto, o desenvolvimento de resistência de $S$. frugiperda à lambda-cialotrina poderia ser considerado uma das possíveis causas para explicar a baixa eficiência desse inseticida registrada no controle de $S$. frugiperda em algumas regiões produtoras de milho no Brasil.

Foi observada uma certa sobreposição das curvas de concentração-resposta das linhagens S e R à lambda-cialotrina (Figura 2). Portanto, não foi possível definir uma concentração discriminatória para estimar a frequêencia de resistência de $S$. frugiperda a esse inseticida. Bioensaios utilizando concentrações discriminatórias são considerados mais apropriados para programas de monitoramento da resistência em populações de campo quando comparados com o procedimento da estimativa da $\mathrm{CL}_{50}$, por apresentar uma maior eficiência e precisão na deteç̧ão de mudanças na freqüência de resistência (Roush \& Miller, 1986; Halliday \& Burnham. 1990; Roush \& Daly, 1990). 


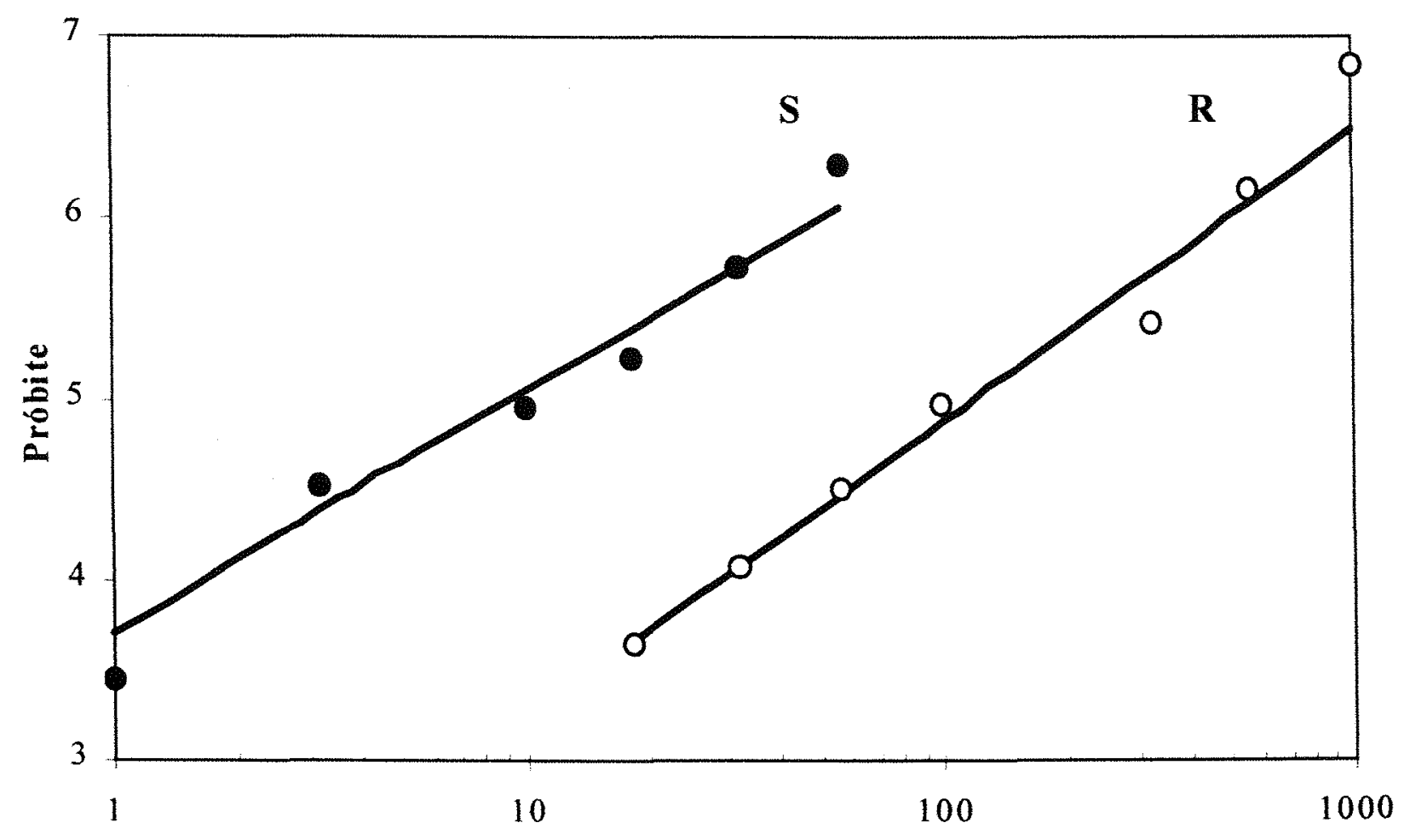

$\mu \mathrm{g}$ de lambda-cialotrina/ $\mathrm{ml}$ acetona

Figura 2. Curvas de concentração-resposta das linhagens susceptível (S) e resistente (R) de $S$. frugiperda à lambda-cialotrina. 
Entretanto, Halliday \& Burnham (1990) recomendaram uma certa precaução no emprego de concentrações diagnósticas para o monitoramento da resistência, principalmente em situações onde existe sobreposição das curvas de concentraçãoresposta, pois a discriminação entre os genótipos não é perfeita. No entanto, concentrações entre 32 e $56 \mu \mathrm{g}$ de lambda-cialotrina $/ \mathrm{ml}$ de acetona poderiam ser utilizadas como concentrações diagnósticas (e não discriminatórias) em programas de monitoramento e manejo da resistência de $S$. frugiperda à lambda-cialotrina.

\subsection{Herança da resistência de Spodoptera frugiperda à lambda-cialotrina}

\subsubsection{Dominância da resistência}

Não foram observadas diferenças nas respostas à lambda-cialotrina para as progênies $F_{1}$ híbridas obtidas a partir dos cruzamentos recíprocos entre as linhagens susceptível (S) e resistente (R) (Tabela 2). Foram verificadas uma sobreposição dos intervalos de confiança das $\mathrm{CL}_{50}$ s e igualdade dos coeficientes angulares estimados para as progênies $F_{1}$ recíprocas através da análise de próbite, o que permite concluir que a resistência de $S$. frugiperda à lambda-cialotrina é autossomal e não ligada ao sexo ou sob efeito maternal (Uyenoyama, 1986; Roush \& Daly, 1990). A razão de resistência para o

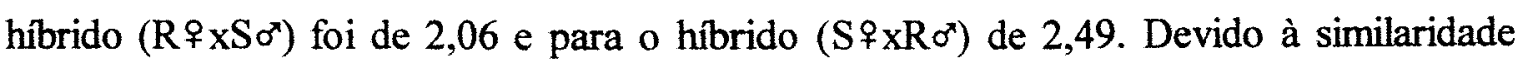
nas respostas das progênies $F_{1}$ recíprocas à lambda-cialotrina, os dados das duas progênies $F_{1}$ foram considerados conjuntamente nas análises posteriores.

Os graus médios de dominância (D) obtidos através da fórmula proposta por Stone (1968) foram de $-0,43$ para o hibrido $\left(\mathrm{R}+\mathrm{xSO}^{7}\right)$ e de $-0,28$ para o hibrido ( $\$ \times \mathrm{xR} \sigma^{\prime}$ ); evidenciando que a resistência de $S$. frugiperda à lambda-cialotrina é incompletamente recessiva (Figura 3). A susceptibilidade à lambda-cialotrina das progênies $F_{1}$ recíprocas foi mais semelhante à da linhagem $\mathrm{S}$. 
Tabela 2. Respostas das $F_{1}$ resultantes de cruzamentos entre as linhagens $S$ e $R$ de S. frugiperda à lambda-cialotrina.

\begin{tabular}{|c|c|c|c|c|c|}
\hline Linhagem & $n^{\mathrm{a}}$ & $\begin{array}{c}\text { CL }_{50} \\
(\mathrm{IC} 95 \%)\end{array}$ & $\begin{array}{c}\text { Coeficiente } \\
\text { Angular }( \pm \mathrm{DP})\end{array}$ & $x^{2}$ & g. $10^{b}$ \\
\hline$\overline{F_{1}}$ & & 18,93 & & & \\
\hline$\left(\mathrm{R} \uparrow \mathrm{xS \sigma ^{* }}\right)$ & 3685 & $(15,51-22,70)$ & $1,67 \pm 0,07$ & 19,20 & 7 \\
\hline $\mathrm{F}_{1}$ & & 22,90 & & & \\
\hline$\left(\mathrm{S} \uparrow \times \mathrm{RO}^{\prime \prime}\right)$ & 2451 & $(19,61-26,74)$ & $1,67 \pm 0,09$ & 6,17 & 5 \\
\hline
\end{tabular}

A herança da resistência incompletamente recessiva para inseticidas piretróides tem sido relatada para outras espécies de lepidópteros, como por exemplo em Plutella xylostella (Liu et al., 1981; Yu, 1993), Heliothis virescens (Payne et al., 1988) e Helicoverpa armigera (Tan \& McCaffery, 1999). Nesses casos, o mecanismo de resistência tem sido devido à insensibilidade do sítio de ação. Por outro lado, casos de herança dominante têm sido reportados para piretróides, onde geralmente a resistência tem sido relacionada ao mecanismo de aumento na destoxificação do inseticida (Daly \& Fisk, 1992, 1993).

O mecanismo de resistência de $S$. frugiperda à lambda-cialotrina não foi estudado na presente pesquisa; porém, caso a resistência seja devido à insensibilidade do alvo de ação (pela recessividade da resistência), todos os piretróides estariam comprometidos através da resistência cruzada.

Sabe-se que a evolução da resistência tende a ser retardada quando é recessiva (Georghiou \& Taylor 1977a; Roush \& McKenzie, 1987). Este fato pode ser explicado através de um exemplo hipotético onde a população de uma praga está em equilibrio de Hardy-Weinberg e a resistência a um determinado inseticida é monogênica e conferida pelos alelos $\mathrm{S}$ e $\mathrm{R}$, responsáveis pela susceptibilidade e resistência, respectivamente. Se a 
freqüência do alelo $\mathrm{S}$ é de 0,9 ; a do alelo $\mathrm{R}$ será de 0,1 . Nestas condições as freqüências genotípicas serão de: 0,81 (SS), 0,18 (SR) e 0,01 (RR). Considerando que a resistência é recessiva, os individuos homozigotos susceptíveis (SS) e os heterozigotos (SR) serão fenotipicamente susceptíveis e irão representar $99 \%$ da população e apenas $1 \%$ serão resistentes (RR). Se a resistência for um caráter dominante, os heterozigotos seriam fenotipicamente resistentes e um 19\% dos indivíduos nesta população sobreviveriam com a aplicação do inseticida. Por outro lado, uma vez que a resistência tenha se estabelecido numa freqüência acima da critica (i.e., freqüência a partir da qual a resistência passa a interferir na eficácia de um produto), o restabelecimento da susceptibilidade ficaria mais dificil nos casos de resistência recessiva. Além do possivel custo adaptativo dos individuos resistentes na ausência de pressão seletiva com o inseticida, a migração de indivíduos susceptiveis de áreas não tratadas poderia contribuir para a redução na freqüência de resistência em um determinado ecossistema (Tabashnik \& Croft, 1982; Georghiou \& Taylor, 1986; Roush, 1989).

A alta habilidade migratória de S. frugiperda (Rose et al., 1975; GutiérrezMartínez et al., 1989; Ferguson et al., 1994), associado ao seu hábito polífago (Barfield et al., 1978; Willink et al., 1991; Rizzo \& La Rossa, 1992) e à incompleta recessividade da resistência à lambda-cialotrina, poderiam ter colaborado para o lento estabelecimento da resistência de $S$. frugiperda a este e a outros inseticidas a níveis críticos no Brasil. No entanto, devido à alta pressão de seleção exercida sobre $S$. frugiperda, principalmente com o advento da cultura de milho safrinha e ao plantio no inverno em propriedades com sistemas de irrigação, o problema de resistência a inseticidas tem se tornado bastante sério em algumas regiões do Brasil nos últimos anos.

\subsubsection{Número de genes}

A hipótese de herança monogênica para a resistência de $S$. frugiperda à lambda-cialotrina foi confirmada mediante a análise das proporções de segregação dos retrocruzamentos da progênie $F_{1}$ com 0 parental resistente, pois segundo as 
recomendações de Tsukamoto (1983) e de Roush \& Daly (1990), o retrocruzamento deve ser realizado com o parental apresentando o fenótipo mais distinto da progênie $F_{1}$. Verificou-se que as mortalidades observadas nos retrocruzamentos $\left(F_{1} \times R\right)$ não foram significativamente diferentes das mortalidades esperadas $\left(\chi^{2}<3,84 ;\right.$ g.l. $\left.=1 ; P>0,05\right)$, exceto para as concentrações de 3,2; 32; 56 e 320 ppm (Tabela 3 e Figura 3).

Tabela 3. Qui-quadrado entre as mortalidades observadas e esperadas dos retrocruzamentos $\left(F_{1} \times R\right)$ para o modelo monogênico (g.l.=1).

\begin{tabular}{cccc}
\hline \multicolumn{4}{c}{ F $_{1} \times \mathbf{R}$} \\
\hline $\begin{array}{c}\text { Concentração } \\
(\mu \mathrm{g} / \mathrm{ml})\end{array}$ & $\begin{array}{c}\text { Mortalidade } \\
\text { Observada (\%) }\end{array}$ & $\begin{array}{c}\text { Mortalidade } \\
\text { Esperada (\%) }\end{array}$ & $\chi^{\mathbf{2}}$ \\
\hline 3,2 & 4,49 & 9,26 & $8,46^{*}$ \\
5,6 & 8,33 & 12,30 & 0,70 \\
10 & 20,07 & 22,84 & 1,24 \\
18 & 25,00 & 28,86 & 1,49 \\
32 & 31,47 & 42,17 & $6,72^{*}$ \\
56 & 44,00 & 52,23 & $7,47^{*}$ \\
100 & 70,49 & 69,93 & 0,03 \\
320 & 88,18 & 82,07 & $7,72^{*}$ \\
\hline
\end{tabular}

\footnotetext{
${ }^{a}$ Mortalidade esperada na concentração $A=0,5$ (\%mortalidade de $F_{1}$ em $A+\%$ mortalidade de $R$ em $A$ ). ' $P<0,05$.
}

Valores de qui-quadrado significativamente altos, podem ser um indício de fatores de variabilidade adicionais influenciando a resistência (Preisler et al., 1990). Portanto, os desvios observados sugerem que a resistência de $S$. frugiperda à lambdacialotrina é determinada por um gene principal sob a influência de alguns genes secundários. 


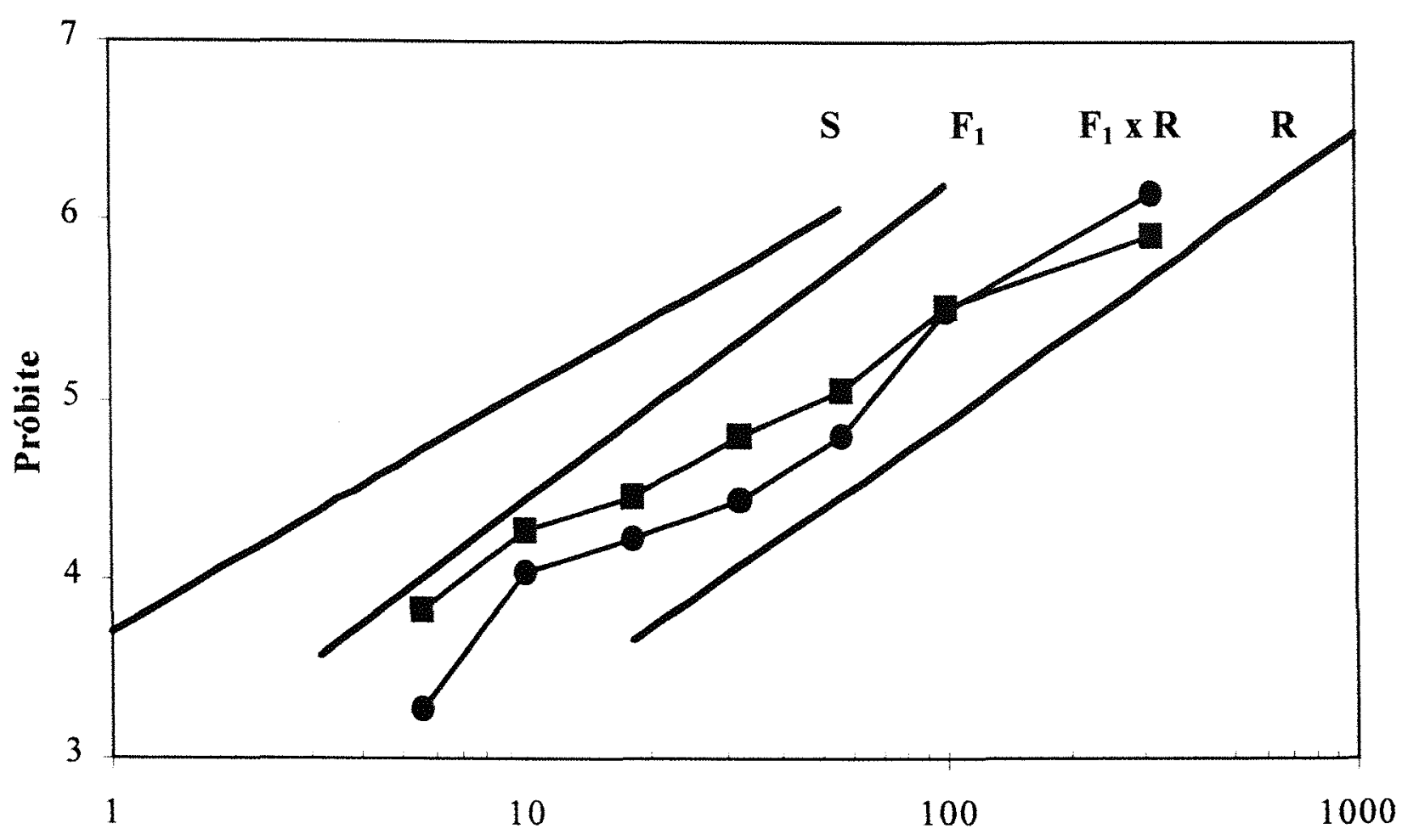

$\mu \mathrm{g}$ de lambda-cialotrina/ $\mathrm{ml}$ acetona

Figura 3. Curvas de concentração-resposta ao inseticida lambda-cialotrina para as linhagens de $S$. frugiperda susceptivel (S), resistente (R), progênies de $\mathrm{F}_{1} \mathrm{e}$ retrocruzamento $\left(F_{1} \times \frac{R}{2}\right)$. Mortalidades esperadas e observadas nos retrocruzamentos são representadas pelos símbolos $\bullet \bullet \bullet$, respectivamente. 
Estes desvios também foram relatados por Halliday \& Georghiou (1985), Roush et al. (1986), Payne et al. (1988) e Osman et al. (1992), onde as mortalidades observadas nas concentrações mais baixas foram menores do que as esperadas, porém maiores nas concentrações mais altas.

Para Halliday \& Georghiou (1985), desvios na mortalidade esperada nos retrocruzamentos, evidenciam a presença de genes secundários localizados em loci separados que segregam independentemente do gene principal em alguns indivíduos. Adicionalmente, Payne et al. (1988) indicaram que mortalidades observadas menores às esperadas podem indicar também, que o gene principal foi mais recessivo que o determinado pelo dado observado e que o(s) gene(s) secundário(s) foram mais dominantes ou intermediários em sua expressão. Whitten (1978) salienta a possibilidade de variações na penetração e expressividade do gene principal e presença de genes secundários, que poderiam interferir no nivel de resistência.

A herança da resistência conferida por um gene principal e sob a influência de genes secundários foi observada também para outras espécies de insetos como $H$. virescens resistente a paration metil (Whitten, 1978), Culex quinquefasciatus (Halliday \& Georghiou, 1985) e Pectinophora gossypiella resistentes à permetrina (Osman et al., 1992) e Haematobia irritans resistente à cipermetrina (Roush et al., 1986).

Freqüentemente um patamar ao redor do $50 \%$ de mortalidade na curva de concentração-resposta das progênies de retrocruzamentos é observada nos casos de herança monogênica da resistência (Tsukamoto, 1983; Roush \& Daly, 1990). Porém, como foi verificada uma certa sobreprosição nas curvas de concentração-mortalidade para as linhagens S e R, este patamar não foi observado (Figura 3). Nesse caso, o uso de marcadores moleculares poderia ser útil para a clarificação da herança monogênica (Roush \& Daly, 1990). 


\subsection{Custo adaptativo da resistência de Spodoptera frugiperda à lambda-cialotrina}

Os dados de parâmetros biológicos das linhagens $S$, isogênica- $R$ e $F_{1}$ híbrida de S. frugiperda são apresentadas a seguir. Esses dados foram utilizados para a confeç̧ão de tabelas de vida de fertilidade para posterior discussão dos resultados obtidos.

$O$ período médio de desenvolvimento larval foi significativamente mais curto na linhagem $F_{1}$ do que nas linhagens $S$ e isogênica- $R$. No entanto, não foram observadas diferenças significativas quanto à viabilidade da fase larval entre as linhagens (Tabela 4).

Pupas tanto de fềmea como de macho da linhagem isogênica- $R$ apresentaram uma menor duração do que as da linhagem $\mathrm{S}$ (Tabela 5). Porém, não foram observadas diferenças significativas na duração do periodo pupal entre as linhagens $S$ e $F_{1}$.

A duração média das pupas de macho foi maior do que a de fềmea (Tabela 5). Com isso, houve uma defasagem na emergência de adultos nas três linhagens, de tal modo que os machos emergiram com um dia de atraso em relação às fềmeas. Esta tendência já foi observada por Parra \& Carvalho (1984), Crocomo \& Parra (1985), Mielitz et al. (1986) e Nalim (1991). Em condições de laboratório, esta característica evitaria o acasalamento entre indivíduos provenientes da mesma progênie, pois de acordo com Crocomo \& Parra (1985) os machos de $S$. frugiperda copulam logo após a sua emergência.

Não foram verificadas diferenças quanto à viabilidade pupal entre as linhagens testadas. Diferenças significativas entre o número de machos e fềmeas foram observadas somente na linhagem isogênica- $R$ que apresentou uma razão sexual de 0,39 ; indicando assim uma predominância de machos (Tabela 6). A razão sexual da linhagem $S($ de 0,48$)$ foi bastante próxima da obtida no trabalho de Kasten et al. (1978) que foi de 0,50.

Quanto ao peso de pupas, não foram observadas diferenças significativas entre as linhagens testadas (Tabela 7). 
Tabela 4. Duração média \pm erro padrão (em dias) e viabilidade (\%) da fase de larva das linhagens de $S$. frugiperda susceptível ( $\mathrm{S}), \mathrm{F}_{1}$ e isogênica- $\mathrm{R}$, à temperatura de $25 \pm 1{ }^{\circ} \mathrm{C}$, UR de $70 \pm 10 \%$ e fotofase de 14 horas.

Linhagens

Duração média (dias)

Viabilidade (\%)

\begin{tabular}{ccc}
\hline$S$ & $24,1 \pm 3,8 \mathrm{a}$ & $76 \mathrm{a}$ \\
$\mathrm{F}_{1}$ & $22,1 \pm 3,0 \mathrm{~b}$ & $70 \mathrm{a}$ \\
Isogênica-R & $24,0 \pm 6,4 \mathrm{a}$ & $86 \mathrm{a}$ \\
\hline
\end{tabular}

Coeficiente de variação $(\%)$ 8,6 29,5

${ }^{\mathrm{a}}$ Dados transformados para are seno $\sqrt{P / 100}$ para análise.

Médias seguidas da mesma letra não diferem estatisticamente entre si, pelo Teste de Tukey, ao nível de $5 \%$ de probabilidade.

Tabela 5. Duração média \pm erro padrão (em dias) de pupas por sexo das linhagens de $S$. frugiperda susceptível (S), $\mathrm{F}_{1}$ e isogênica- $\mathrm{R}$, à temperatura de $25 \pm 1^{\circ} \mathrm{C}$, UR de $70 \pm 10 \%$ e fotofase de 14 horas.

Linhagens

\section{Duração média (dias)}

\begin{tabular}{ccc}
\cline { 2 - 3 } & \multicolumn{1}{c}{$\sigma^{7}$} \\
\hline $\mathrm{S}$ & $11,4 \pm 0,8 \mathrm{a}$ & $12,4 \pm 0,8 \mathrm{a}$ \\
$\mathrm{F}_{1}$ & $11,2 \pm 0,6 \mathrm{ab}$ & $12,5 \pm 0,8 \mathrm{a}$ \\
Isogênica-R & $11,0 \pm 0,7 \mathrm{~b}$ & $12,1 \pm 0,7 \mathrm{~b}$ \\
\hline
\end{tabular}

Coeficiente de variação (\%)

1,9 1,7

Médias seguidas da mesma letra não diferem estatisticamente entre si, pelo Teste de Tukey, ao nível de $5 \%$ de probabilidade. 
Tabela 6. Viabilidade (\%) e razão sexual da fase de pupa das linhagens de $S$. frugiperda susceptível $(\mathrm{S}), \mathrm{F}_{1}$ e isogênica- $\mathrm{R}$, à temperatura de $25 \pm 1^{\circ} \mathrm{C}$, UR de $70 \pm 10 \%$ e fotofase de 14 horas.

Linhagens

Viabilidade (\%)

Razão sexual

\begin{tabular}{ccl}
\hline $\mathrm{S}$ & $94 \mathrm{a}$ & 0,48 \\
$\mathrm{~F}_{1}$ & $90 \mathrm{a}$ & 0,44 \\
Isogênica-R & $92 \mathrm{a}$ & $0,39^{*}$ \\
\hline
\end{tabular}

Coeficiente de variação (\%) 13,5

${ }^{a}$ Dados transformados para arc seno $\sqrt{P / 100}$ para análise.

Médias seguidas da mesma letra não diferem estatisticamente entre si, pelo Teste de Tukey, ao nível de $5 \%$ de probabilidade.

* Teste $\chi^{2}(\mathrm{P}<0,05)$.

Tabela 7. Peso médio \pm erro padrão (em $\mathrm{mg}$ ) de pupas por sexo das linhagens de $S$. frugiperda susceptivel (S), $\mathrm{F}_{1}$ e isogênica- $\mathrm{R}$, à temperatura de $25 \pm 1^{\circ} \mathrm{C}, \mathrm{UR}$ de $70 \pm 10 \%$ e fotofase de 14 horas.

\section{Linhagens}

\section{Peso médio (mg)}

\begin{tabular}{ccc}
\cline { 2 - 3 } & \multicolumn{1}{c}{${ }^{*}$} \\
\hline $\mathrm{S}$ & $242,0 \pm 44,9 \mathrm{a}$ & $238,7 \pm 34,2 \mathrm{a}$ \\
$\mathrm{F}_{1}$ & $235,6 \pm 34,9 \mathrm{a}$ & $243,9 \pm 30,2 \mathrm{a}$ \\
Isogênica-R & $252,6 \pm 38,9 \mathrm{a}$ & $226,1 \pm 40,5 \mathrm{a}$ \\
\hline
\end{tabular}

Coeficiente de variação (\%)

4,9 5,5

Médias seguidas da mesma letra não diferem estatisticamente entre si, pelo Teste de Tukey, ao nivel de $5 \%$ de probabilidade. 
Fêmeas da linhagem isogênica- $R$ apresentaram uma menor longevidade do que a da linhagem $F_{1}$. No entanto, não foram observadas diferenças significativas entre as longevidades das linhagens $\mathrm{S}$ e isogênica- $\mathrm{R}$. A longevidade de machos para as três linhagens foi semelhante (Tabela 8).

A fecundidade foi significativamente superior para a linhagem isogênica- $R$ quando comparada com a linhagem S. Não foram verificadas diferenças significativas na fecundidade entre as linhagens $\mathrm{S}$ e $\mathrm{F}_{1}$ (Tabela 9).

$\mathrm{O}$ período de pré-oviposição foi significativamente mais longo para a linhagem S. Os maiores periodos de oviposição foram observados para as linhagens $F_{1}$ e isogênica- $R$ (Tabela 10 ).

A duração da fase de ovo não diferiu entre as linhagens (Tabela 11). A viabilidade de ovos para a linhagem $F_{1}$ foi significativamente superior às das linhagens $\mathrm{S} e$ isogênica- $R$ (Tabela 11). Os valores observados para a viabilidade de ovos foram bastante baixos para as três linhagens estudadas quando comparados com os valores reportados por Burton \& Perkins (1972) e Ferraz (1982) em dieta artificial. Não obstante Kasten et al. (1978) obtiveram uma viabilidade de $54,5 \%$, semelhante à observada para a linhagem $\mathrm{F}_{1}$, para uma população de $S$. frugiperda criada também em dieta à base de germe de trigo. Estes resultados poderiam ser atribuídos à danificação mecânica de ovos no momento da transferência com a utilização de um pincel para o isolamento de ovos. No entanto, uma outra explicação mais plausivel para a baixa viabilidade de ovos no presente estudo pode ser devida à ausência de fertilização; pois foi verificado que os ovos das primeiras posturas apresentavam uma coloração predominantemente esverdeada.

Segundo Nalim (1991), a viabilidade de posturas com ovos esverdeados foi de aproximadamente $29 \%$, quando lagartas de $S$. frugiperda foram criadas na mesma dieta utilizada no presente estudo. Para evitar esse problema em trabalhos futuros, o acasalamento de vários casais dentro de uma mesma gaiola garantiria talvez uma maior viabilidade de ovos.

Os menores períodos de ovo a adulto foram observados para as linhagens isogênica- $R$ e $F_{1}$ (Tabela 12). 
Tabela 8. Longevidade média \pm erro padrão (em dias) de adultos por sexo das linhagens de $S$. frugiperda susceptivel (S), $\mathrm{F}_{1}$ e isogênica- $\mathrm{R}$, à temperatura de $25 \pm 1^{\circ} \mathrm{C}$, UR de $70 \pm 10 \%$ e fotofase de 14 horas.

\section{Linhagens}

\section{Longevidade média (dias)}

\begin{tabular}{ccc}
\cline { 2 - 3 } & \multicolumn{1}{c}{$\sigma^{*}$} \\
\hline$S$ & $12,8 \pm 5,4 \mathrm{ab}$ & $12,7 \pm 3,9 \mathrm{a}$ \\
$\mathrm{F}_{1}$ & $15,0 \pm 6,9 \mathrm{a}$ & $10,9 \pm 4,2 \mathrm{a}$ \\
Isogennica-R & $10,5 \pm 5,3 \quad \mathrm{~b}$ & $11,8 \pm 5,9 \mathrm{a}$ \\
\hline
\end{tabular}

Coeficiente de variação (\%) 46,3

40,2

Médias seguidas da mesma letra não diferem estatisticamente entre si, pelo Teste de Tukey, ao nivel de $5 \%$ de probabilidade.

Tabela 9. Número médio de ovos por fềmea \pm erro padrão das linhagens de $S$. frugiperda susceptivel (S), $\mathrm{F}_{1}$ e isogênica- $\mathrm{R}$, à temperatura de $25 \pm 1^{\circ} \mathrm{C}$, UR de $70 \pm 10 \%$ e fotofase de 14 horas.

Linhagens

Média ovos/우

\begin{tabular}{cc}
\hline$S$ & $605,9 \pm 664,7 \quad b$ \\
$F_{1}$ & $824,0 \pm 875,9 \quad a b$ \\
Isogênica-R & $1381,1 \pm 1073,0 \mathrm{a}$ \\
\hline
\end{tabular}

Coeficiente de variação (\%) 94,7

Médias seguidas da mesma letra não diferem estatisticamente entre si, pelo Teste de Tukey, ao nivel de $5 \%$ de probabilidade. 
Tabela 10. Duração média \pm erro padrão (em dias) dos períodos de pré-oviposição e oviposição das linhagens de $S$. frugiperda susceptível $(\mathrm{S}), \mathrm{F}_{1}$ e isogênica- $\mathrm{R}$, à temperatura de $25 \pm 1{ }^{\circ} \mathrm{C}$, UR de $70 \pm 10 \%$ e fotofase de 14 horas.

Linhagens

Pré-oviposição (dias)

Oviposição (dias)

\begin{tabular}{ccl}
\hline$S$ & $5,9 \pm 4,0 \mathrm{a}$ & $4,9 \pm 2,2 \mathrm{~b}$ \\
$\mathrm{~F}_{1}$ & $4,1 \pm 1,4 \mathrm{ab}$ & $8,9 \pm 4,1 \mathrm{a}$ \\
Isogênica-R & $3,3 \pm 1.4 \mathrm{~b}$ & $6,5 \pm 4,7 \mathrm{ab}$ \\
\hline
\end{tabular}

Coeficiente de variação (\%)

56,5

57,4

Médias seguidas da mesma letra não diferem estatisticamente entre si, pelo Teste de Tukey, ao nível de $5 \%$ de probabilidade.

Tabela 11. Duração média \pm erro padrão (em dias) e viabilidade (\%) da fase de ovo das linhagens de $S$. frugiperda susceptivel (S), $\mathrm{F}_{1}$ e isogênica- $\mathrm{R}$, à temperatura de $25 \pm 1^{\circ} \mathrm{C}$, UR de $70 \pm 10 \%$ e fotofase de 14 horas.

Linhagens

Duração média (dias)

Viabilidade (\%)

\begin{tabular}{ccc}
\hline$S$ & $3,0 \pm 0,1 \mathrm{a}$ & $11 \mathrm{~b}$ \\
$\mathrm{~F}_{1}$ & $3,0 \pm 0,0 \mathrm{a}$ & $53 \mathrm{a}$ \\
Isogênica-R & $3,1 \pm 0,2 \mathrm{a}$ & $20 \mathrm{~b}$ \\
\hline
\end{tabular}

Coeficiente de variação (\%) 4.2 136,7

${ }^{a}$ Dados transformados para arc seno $\sqrt{P / 100}$ para análise.

Médias seguidas da mesma letra não diferem estatisticamente entre si, pelo Teste de Tukey, ao nível de $5 \%$ de probabilidade. 
Tabela 12. Duração média \pm erro padrão (em dias) do período ovo-adulto das linhagens de $S$. frugiperda susceptivel (S), $\mathrm{F}_{1}$ e isogênica-R, à temperatura de $25 \pm$ $1^{\circ} \mathrm{C}$, UR de $70 \pm 10 \%$ e fotofase de 14 horas.

\section{Linhagens} $\mathrm{S}$

$F_{1}$

Isogênica-R

\section{Duração média (dias)}

$$
\begin{aligned}
& 50,0 \pm 4,8 \mathrm{a} \\
& 48,7 \pm 5,7 \text { ab } \\
& 44,8 \pm 5,9 \quad \mathrm{~b}
\end{aligned}
$$

Coeficiente de variação (\%) 4,3

Médias seguidas da mesma letra não diferem estatisticamente entre si, pelo Teste de Tukey, ao nível de $5 \%$ de probabilidade.

Com a elaboração de tabelas de vida de fertilidade para a três linhagens (Tabela 13), foi observado que não há custo adaptativo para as linhagens isogênica-R e $F_{1}$. As diferenças nos valores relativos à taxa líquida de reprodução $\left(R_{0}\right)$ foram mais expressivos entre as linhagens do que a duração média de uma geração $(T)$. As linhagens isogênica- $R$ e $F_{1}$, se mostraram até mais adaptadas na ausência de pressão seletiva com lambdacialotrina do que a linhagem $S$.

De acordo com as teorias de evolução, o gene que confere a resistência a um determinado inseticida estaria associado a alguma desvantagem adaptativa no início do desenvolvimento da resistência; caso contrário, os alelos resistentes seriam predominantes mesmo antes do início do uso de um determinado inseticida (Crow, 1957; Georghiou, 1983). No entanto, existe a possibilidade de uma coadaptação no decorrer do processo evolutivo através da incorporação de genes modificadores na linhagem resistente para aumentar o seu valor adaptativo (Georghiou, 1972; Roush \& McKenzie, 1987). Por esta razão, para avaliar o custo adaptativo da resistência no presente estudo foi criada uma linhagem isogênica, na tentativa de isolar o gene que confere resistência à lambda- 
cialotrina dentro do genoma susceptivel, para eliminar o efeito de possíveis genes modificadores.

Após três ciclos de retrocruzamentos seguidos de intercruzamentos, devido ao caráter incompletamente recessivo da resistência de $S$. frugiperda à lambda-cialotrina, houve uma incorporação de aproximadamente $94 \%$ do genoma da linhagem susceptível (S) na linhagem considerada isogênica-R. Portanto, 6\% do genoma da linhagem isogênica- $R$ foi proveniente da linhagem $R$, e sendo assim, os genes modificadores do valor adaptativo poderiam estar ainda presentes na linhagem isogênica-R.

Vários estudos reportados na literatura também têm demonstrado a ausência de custo adaptativo da resistência (Varzandeh et al., 1954 ; Omer et al., 1992; Glenn et al., 1994; Tang et al., 1997). No entanto, esses resultados poderiam estar sob a influência de genes modificadores do valor adaptativo, uma vez que os trabalhos não foram conduzidos com linhagens isogênicas.

Tabela 13. Parâmetros biológicos obtidos através da tabela de vida de fertilidade para as linhagens de $S$. frugiperda susceptivel (S), $\mathrm{F}_{1}$ e isogênica-R: duração média de uma geração $(T)$, taxa líquida de reprodução $\left(R_{0}\right)$, capacidade inata de aumentar em número $\left(r_{m}\right)$ e razão finita de aumento $(\lambda)$.

\section{Parâmetros biológicos}

\begin{tabular}{ccccc} 
Linhagens & \multicolumn{4}{c}{} \\
\cline { 2 - 5 } & $\begin{array}{c}\boldsymbol{T} \\
\text { (dias) }\end{array}$ & $\boldsymbol{R}_{\boldsymbol{\theta}}$ & $\boldsymbol{r}_{\boldsymbol{m}}$ & $\boldsymbol{\lambda}$ \\
\hline $\mathrm{S}$ & 45,97 & 26,64 & 0,07 & 1,073 \\
$\mathrm{~F}_{1}$ & 42,63 & 116,70 & 0,11 & 1,116 \\
Isogênica-R & 43,99 & 94,47 & 0,10 & 1,105 \\
\hline
\end{tabular}

O custo adaptativo de indivíduos resistentes na ausência de pressão de seleção poderia ser explorado em estratégias de manejo da resistência, tais como o manejo por 
moderação ou por ataque múltiplo através da rotação de pesticidas (Georghiou, 1983). No presente estudo, tais desvantagens adaptativas não foram verificadas, e os individuos resistentes mostraram-se até mais adaptados do que os susceptíveis na ausência de seleção. Porém, vale salientar que talvez o custo adaptativo esteja associado a outros parâmetros que não foram avaliados no presente estudo como a susceptibilidade a inimigos naturais, capacidade de produção de feromônios, habilidade para o acasalamento, etc. Sendo assim, para avaliar o custo adaptativo seria interessante testar a freqüência de resistência de $S$. frugiperda à lambda-cialotrina em condições de campo na ausência de pressão seletiva.

Apesar dos estudos de valor adaptativo associados com resistência serem mais realísticos quando conduzidos no campo, existem uma série de limitações particularmente porque a freqüência de indivíduos resistentes pode declinar como conseqüência da migração de indivíduos susceptíveis e não por desvantagens adaptativas. Por isso, esses estudos são desenvolvidos no laboratório, embora os resultados possam ser muitas vezes mascarados (Roush \& Daly, 1990).

A herança da resistência de $S$. frugiperda a lambda-cialotrina foi identificada como recessiva, autossomal e monogênica no presente estudo. Sendo assim, os indivíduos heterozigotos se comportam como os susceptíveis com relação à susceptibilidade ao inseticida lambda-cialotrina. Por outro lado, em termos de capacidade adaptativa na ausência de pressão seletiva, os heterozigotos se comportam mais como os indivíduos resistentes homozigotos. Estas características conferem uma maior estabilidade da resistência em condições de campo, uma vez que a resistência de $S$. frugiperda à lambda-cialotrina atinja níveis críticos em uma determinada população. Sendo assim, estratégias de manejo da resistência devem ser implementadas com urgência para preservar a vida útil desse importante inseticida no controle de $S$. frugiperda. 


\section{CONCLUSÕES}

- A herança da resistência de Spodoptera frugiperda à lambda-cialotrina é autossomal e incompletamente recessiva.

- A resistência de $S$. frugiperda à lambda-cialotrina é determinada por um gene principal, sob a influência de alguns genes secundários.

- Não existe custo adaptativo da resistência de $S$. frugiperda à lambda-cialotrina com relação aos parâmetros biológicos avaliados. 


\section{REFERÊNCIAS BIBLIOGRÁFICAS}

ALYOKHIN, A.V.; FERRO, D.N. Relative fitness of colorado potato beetle (Coleoptera: Chrysomelidae) resistant and susceptible to the Bacillus thuringiensis Cry3 A toxin. Journal of Economic Entomology, v.92, n.3, p.510-515, Jun. 1999.

AMIN, A.M.; WHITE, G.B. Relative fitness of organophosphate-resistant and susceptible strains of Culex quinquefasciatus Say (Diptera: Culicidae). Bulletin of Entomological Research, v.74, p.591-598, 1984.

ARGENTINE, J.A.; MARSHALL CLARK, J.; FERRO, D.N. Relative fitness of insecticide-resistant colorado potato beetle strains (Coleoptera: Chrysomelidae). Environmental Entomology, v.18, n.4, p.705-710, Aug. 1989.

BAILEY, D.L.; CHADA, H.L. Effects of natural (sorghum) and artificial (wheat germ) diets on development of the corn earworm, fall armyworm, and southwestern corn borer. Journal of Economic Entomology, v.61, n.1, p. 257-260, Feb. 1968.

BARFIELD, C.S.; MITCHELL, E.R.; POE, S.L. A temperature-dependent model for fall armyworm development. Annals of the Entomological Society of America, v.71, n.1, p.70-74, Jan. 1978.

BRATTSTEN, L.B.; HOLYOKE Jr., C.W.; LEEPER, J.R. et al. Insecticide resistance: challenge to pest management and basic research. Science, v.231, p.1255-1260. Mar. 1986. 
BURTON, R.L.; PERKINS, W.D. WSB, a new laboratory diet for the corn earworm and the fall armyworm. Journal of Economic Entomology, v.65, n.2, p.385-386, Apr. 1972.

CAMPANHOLA, C.; McCUTCHEN, B.F.; BAEHRECKE, E.H. et al. Biological constraints associated with resistance to pyrethroids in the tobacco budworm (Lepidoptera: Noctuidae). Journal of Economic Entomology, v.84, n.5, p.14041411, Oct. 1991.

CROCOMO, W.B.; PARRA, J.R.P. Desenvolvimento de Spodoptera frugiperda (J.E. Smith, 1797) (Lepidoptera, Noctuidae) sobre milho, trigo e sorgo. Revista Brasileira de Entomologia, v.29, n.2, p.363-368, 1985.

CROW, J.F. Genetics of insecticide resistance to chemicals. Annual Review of Entomology, v.2, p.227-246, 1957.

CRUZ, I. Manejo integrado de pragas de milho com ênfase para o controle biológico. In: 4 CICLO DE PALESTRAS SOBRE CONTROLE BIOLÓGICO DE PRAGAS, 4, Campinas, 1995. Anais. Campinas: Instituto Biológico,1995. p.48-92.

CRUZ, I.; VIANA, P.A.; WAQUIL, J.M. et al. Pragas: Diagnóstico e Controle. Arquivo do Agrônomo, v.2, p.9-21, 1995.

DALY, J.C.; FISK, J.H. Inheritance of metabolic resistance to the synthetic pyrethroids in australian Helicoverpa armigera (Lepidoptera: Noctuidae). Bulletin of Entomological Research, v.82, p.5-12, 1992.

DALY, J.C.; FISK, J.H. Expression of pyrethroid resistance in adult Helicoverpa armigera (Lepidoptera: Noctuidae) and selective mortality in field populations. Bulletin of Entomological Research, v.83, p.23-28, 1993. 
DENNEHY, T.J.; NYROP, J.P.; MARTINSON, T.E. Characterization and exploitation of instability of spider mite resistance to acaricides. In: GREEN, M.B.; LeBARON, H.M.; MOBERG, W.K. (Ed.) Managing resistance to agrochemicals: from fundamental research to practical strategies. Washington: American Chemical Society, 1990. cap. 5, p.77-91.

EL-KHATIB, Z.I.; GEORGHIOU, G.P. Comparative fitness of temephos-resistant, susceptible, and hybrid phenotypes of the southern house mosquito (Diptera: Culicidae). Journal of Economic Entomology, v.78, p.1023-1029, Oct. 1985.

ELZEN, G.W.; MARTIN, S.H.; LEONARD, B.R. et al. Inheritance, stability, and reversion of insecticide resistance in tobacco budworm (Lepidoptera: Noctuidae) field populations. Journal of Economic Entomology, v.87, n.3, p.551-558, Jun. 1994.

FERGUSON, H.J.; EATON, J.L.; ROGERS, C.E. et al. Rearing density effects on pupal weight, wing width, development, and female adult activity of the fall armyworm (Lepidoptera: Noctuidae). Annals of the Entomological Society of America, v.87, n.6, p.823-830, Nov. 1994.

FERRARI, J.A.; GEORGHIOU, G.P. Effects on insecticidal selection and treatment on reproductive potential of resistant, susceptible, and heterozygous strains of the southern house mosquito. Journal of Economic Entomology, v.74, p.323-327, Jun. 1981.

FERRAZ, M.C.V.D. Determinação das exigências térmicas de Spodoptera frugiperda (J.E. Smith, 1797) (Lepidoptera, Noctuidae) em cultura de milho. Piracicaba, 1982. 81p. Dissertação (Mestrado) - Escola Superior de Agricultura "Luiz de Queiroz", Universidade de São Paulo. 
FOSTER, S.P.; WOODCOCK, C.M.; WILLIAMSON, M.S. et al. Reduced alarm response by peach-potato aphids, Myzus persicae (Hemiptera: Aphididae), with knock-down resistance to insecticides (kdr) may impose a fitness cost through increased vulnerability to natural enemies. Bulletin of Entomological Research, - v.89, p.133-138, 1999.

FFRENCH-CONSTANT, R.H.; ROUSH, R.T. Resistance detection and documentation: the relative roles of pesticidal and biochemical assays. .In: ROUSH, R.T.; TABASHNIK, B.E. (Ed.) Pesticide resistance in arthropods. New York: Chapman and Hall, 1990. cap. 2, p.4-38.

FUTUYMA, D.J. Biologia evolutiva. Riberão Preto: Sociedade Brasileira de Genética. CNPq, 1993. $646 \mathrm{p}$.

GEORGHIOU, G.P. The evolution of resistance to pesticides. Annual Review of Ecology and Systematics, v.3, p.133-168, 1972.

GEORGHIOU, G.P. Management of resistance in arthropods. In: GEORGHIOU, G.P.; SAITO, T. (Ed.) Pest resistance to pesticides. New York: Plenum, 1983. p.769792.

GEORGHIOU, G.P.; TAYLOR, C.E. Genetic and biological influences in the evolution of insecticide resistance. Journal of Economic Entomology, v.70, n.3, p.319-323, Jun. 1977a.

GEORGHIOU, G.P.; TAYLOR, C.E. Operational influences in the evolution of insecticide resistance. Journal of Economic Entomology, v.70, n.5, p.653-658, Oct. $1977 b$.

GEORGHIOU, G.P.; TAYLOR, C.E. Factors influencing the evolution of resistance. In: NATIONAL RESEARCH COUNCIL. Pesticide resistance: strategies and tactics for management. Washington: National Academy Press, 1986. p.157-169. 
GLENN, D.C.; HOFFMANN, A.A.; McDONALD, G. Resistance to pyrethroids in Helicoverpa armigera (Lepidoptera: Noctuidae) from corn: adult resistance, larval resistance, and fitness effects. Journal of Economic Entomology, v.87, n.5, p.1165-1171, Oct.1994.

GUTIÉRREZ-MARTÍNEZ, A.; LLANDERAL CÁZARES, C.; ZÁRATE DE LARA, G. et al. Fluctuación poblacional de Spodoptera frugiperda (J.E. Smith) (Lepidoptera: Noctuidae). Agrociencia, n.76, p.167-174, 1989.

HALLIDAY, W.R.; BURNHAM, K.P. Choosing the optimal diagnostic dose for monitoring insecticide resistance. Journal of Economic Entomology, v.83, n.4, p.1151-1159, Aug.1990.

HALLIDAY, W.R.; GEORGHIOU, G.P. Inheritance of resistance to permethrin and DDT in the southern house mosquito (Diptera: Culicidae). Journal of Economic Entomology, v.78, p.762-767, Aug. 1985.

HAMMOCK, B.D.; SODERLUND, D.M. Chemical strategies for resistance management. In: NATIONAL RESEARCH COUNCIL. Pesticide resistance: strategies and tactics for management. Washington: National Academy Press, 1986. p.111-129.

HOLLOWAY, G.J. A theoretical examination of the classical theory of inheritance of insecticide resistance and the genetics of time to knockdown and dry body weight in Sitophilus oryzae (L.) (Coleoptera: Curculionidae). Bulletin of Entomological Research, v.76, p.661-670, 1986.

HOSKINS, W.M.; GORDON, H.T. Arthropod resistance to chemicals. Annual Review of Entomology, v.1, p.89-122, 1956. 
KASTEN Jr., P.; PRECETTI, A.A.C.M.; PARRA, J.R.P. Dados biológicos comparativos de Spodoptera frugiperda (J. E. Smith, 1797) em duas dietas artificiais e substrato natural. Revista de Agricultura, Piracicaba, v.53, n.1/2, p.68$78,1978$.

LEEPER, J.R.; ROUSH, R.T.; REYNOLDS, H.T. Preventing or managing resistance in arthropods. In: NATIONAL RESEARCH COUNCIL. Pesticide resistance: strategies and tactics for management. Washington: National Academy Press, 1986. p.335-346.

LEORA SOFTWARE. POLO-PC: a user's guide to Probit Or LOgit analysis. Berkeley, 1987. $20 \mathrm{p}$.

LEUCK, D.B.; PERKINS, W.D. A method of estimating fall armyworm progeny reduction when evaluating control achieved host-plant resistance. Journal of Economic Entomology, v.65, p.482-483, 1972.

LIU, M.Y.; TZENG, Y.J.; SUN, C.N. Diamondback moth resistance to several synthetic pyrethroids. Journal of Economic Entomology, v.74, p.393-396, Aug. 1981.

McCORD Jr., E.; YU, S.J. The mechanisms of carbaryl resistance in the fall armyworm, Spodoptera frugiperda (J.E. Smith). Pesticide Biochemistry and Physiology, v.7, n.1, p.114-122, 1987.

McDONALD, P.T.; SCHMIDT, C.D. Genetics of permethrin resistance in the horn fly (Diptera: Muscidae). Journal of Economic Entomology, v.80, p.433-437, Apr. 1987.

McKENZIE, J.A. Ecological and evolutionary aspects of insecticide resistance. Austin: Academic Press, 1996. 185 p. 
McKENZIE, J.A. The character or the variation: the genetic analysis of the insecticideresistance phenotype. Bulletin of Entomological Research, v.90, p.3-7, 2000.

METCALF, R.L. Changing role of insecticides in crop protection. Annual Review of Entomology, v.25, p.219-256, 1980.

METCALF, R.L. Implications and prognosis of resistance to insecticides. In: GEORGHIOU, G.P.; SAITO, T. (Ed.) Pest resistance to pesticides. New York: Plenum, 1983. p.703-733.

MIELITZ, L.R.; CORSEUIL, E.; SOARES, C.M.S. Efeito do germe de trigo em dieta artificial sobre Spodoptera frugiperda (J.E. Smith, 1797) (Lepidoptera, Noctuidae). Anais da Sociedade Entomológica do Brasil, v.15, p.105-115, 1986. Suplemento.

NALIM, D.M. Biologia, nutrição quantitativa e controle de qualidade de populações de Spodoptera frugiperda (J.E. Smith, 1797) (Lepidoptera: Noctuidae) em duas dietas artificiais. Piracicaba, 1991. 150p. Tese (Doutorado) - Escola Superior de Agricultura "Luiz de Queiroz", Universidade de São Paulo.

NATIONAL RESEARCH COUNCIL. Pesticide Resistance: Strategies and Tactics for Management. Washington: National Academy Press, 1986. 471 p.

OMER, A.D.; LEIGH, T.F.; GRANETT, J. Insecticide resistance of greenhouse whitefly (Hom., Aleyrodidae) and fitness on plant hosts relative to the San Joaquin Valley (California) cotton agroecosystem. Journal of Applied Entomology, v.113, p.244-251, 1992.

OSMAN, A.A.; WATSON, T.F.; SIVASUPRAMANIAM, S. Inheritance of permethrin resistance in the Pink Bollworm (Lepidoptera: Gelechiidae). Journal of Economic Entomology, v.85, n.2, p.335-339, Apr. 1992.

PARRA, J.R.P. Técnicas de criação de insetos para programas de controle biológico. Piracicaba: ESALQ/FEALQ, 1996. 137p. 
PARRA, J.R.P.; CARVALHO, S.M. de. Biologia e nutrição quantitativa de Spodoptera frugiperda (J.E. Smith, 1797) em meios artificiais compostos de diferentes variedades de feijão. Anais da Sociedade Entomológica do Brasil, v.13, n.2, p.305-319, 1984.

PAYNE, G.T.; BLENK, R.G.; BROWN, T.M. Inheritance of permethrin resistance in the tobacco budworm (Lepidoptera: Noctuidae). Journal of Economic Entomology, v.81, n.1, p.65-73, Feb. 1988.

PENCOE, N.L.; MARTIN, P.B. Development and reproduction of fall armyworm on several wild grasses. Environmental Entomology, v.10, p.999-1002, Dec. 1981.

PERKINS Jr., B.D.; GRAYSON, J.M. Some biological comparisons of resistant and nonresistant strains of the german cockroach, Blattella germanica. Journal of Economic Entomology, v.54, n.4, p.747-750, Aug. 1961.

PERKINS, W.D.; JONES, R.L.; SPARKS, A.N. et al. Artificial diet for mass rearing of corn earworm (Heliothis zea). ARS. USDA, Prod. Res. Report. n. 154, 1973. $7 \mathrm{p}$.

PLAPP Jr., F.W. Genetics and biochemistry of insecticide resistance in arthropods: prospects for the future. In: NATIONAL RESEARCH COUNCIL. Pesticide resistance: strategies and tactics for management. Washington: National Academy Press, 1986. p.74-86.

PLAPP Jr, F.W.; BROWNING, C.R.; SHARPE, P.J.H. Analysis of the rate of development of insecticide resistance based on simulation of a genetic model. Environmental Entomology, v.8, p.494-500, 1979.

PREISLER, H.K.; HOY, M.A.; ROBERTSON, J.L. Statistical analysis of modes of inheritance for pesticide resistance. Journal of Economic Entomology, v.83, n.5, p.1649-1655, 1990. 
RIZZO, H.F.; LA ROSSA, F.R. Aspectos morfológicos y biológicos de la "oruga militar tardía" (Spodoptera frugiperda (J.E. Smith)) (Lep.: Noctuidae). Revista de la Facultad de Agronomía de la Universidad de Buenos Aires, v.13, n.2/3, p.193-199, 1992.

ROSE, A.H.; SILVERSIDES, R.H.; LINDQUIST, O.H. Migration flight by an aphid, Rhopalosiphum maidis (Hemiptera: Aphididae), and a noctuid, Spodoptera frugiperda (Lepidoptera: Noctuidae). The Canadian Entomologist, v.107, p.567576, Jun. 1975.

ROUSH, R.T. Designing resistance management programs: how can you choose? Pesticide Science, v.26, p.423-441, 1989.

ROUSH, R.T.; CROFT, B.A. Experimental population genetics and ecological studies of pesticide resistance in insects and mites. In: NATIONAL RESEARCH COUNCIL. Pesticide resistance: strategies and tactics for management. Washington: National Academy Press, 1986. p.257-270.

ROUSH, R.T.; DALY, J.C. The role of population genetics in resistance research and management. In: ROUSH, R.T.; TABASHNIK, B.E. (Ed.) Pesticide resistance in arthropods. New York: Chapman and Hall, 1990. cap. 5, p.97-152.

ROUSH, R.T.; HOY, M.A. Laboratory, glasshouse, and field studies of artificially selected carbaryl resistance in Metaseiulus occidentalis. Journal of Economic Entomology, v.74, p.142-147, Apr. 1981.

ROUSH, R.T.; McKENZIE, J.A. Ecological genetics of inseticide and acaricide resistance. Annual Review of Entomology, v.32, p.361-380, 1987.

ROUSH, R.T.; MILLER, G.L. Considerations for design of insecticide resistance monitoring programs. Journal of Economic Entomology, v.79, p.293-298, Apr. 1986. 
ROUSH, R.T.; PLAPP Jr., F.W. Effects of insecticide resistance on biotic potential of house fly (Diptera: Muscidae). Journal of Economic Entomology, v.75, p.708713, Aug. 1982.

ROUSH, R.T.; COMBS, R.L.; RANDOLPH, T.C. et al. Inheritance and effective dominance of pyrethroid resistance in the horn fly (Diptera: Muscidae). Journal of Economic Entomology, v.79, p.1178-1182, Oct. 1986.

SAWICKI, R.M. Definition, detection and documentation of insecticide resistance. In: FORD, M.G.; HOLLOMAN, D.W.; KHAMBAY, B.P.S.; SAWICKI, R.M. (Ed.) Combating resistance to xenobiotics: biological and chemical approaches. Chichester: Ellis Horwood, 1987. p.105-107.

SEONG NG, S.; DAVIS, F.M.; REESE, J.C. Southwestern corn borer (Lepidoptera: Pyralidae) and fall armyworm (Lepidoptera: Noctuidae): comparative developmental biology and food consumption and utilization. Journal of Economic Entomology, v.86, n.2, p.394-400, Apr. 1993.

SILVEIRA NETO, S.; NAKANO, O.; BARBIN, D. et al. Manual de Ecologia dos insetos. São Paulo: Ceres, 1976. 419p.

STONE, B.F. A formula for determining the degree of dominance in cases of monofactorial inheritance of resistance to chemicals. Bulletin of World Health Organization, v.38, p.325-326, 1968.

TABASHNIK, B.E. Determining the mode of inheritance of pesticide resistance with backcross experiments. Journal of Economic Entomology, v.84, n.3, p.703-712, Jun. 1991.

TABASHNIK, B.E.; CROFT, B.A. Managing pesticide resistance in crop-arthropod complexes: interactions between biological and operational factors. Environmental Entomology, v.11, n.6, p.1137-1144, Dec.1982. 
TABASHNIK, B.E.; CUSHING, N.L. Quantitative genetics analysis of insecticide resistance: variation in fenvalerate tolerance in a diamondback moth (Lepidoptera: Plutellidae) population. Journal of Economic Entomology, v.82, n.1, p.5-10, Feb. 1989.

TABASHNIK, B.E.; SCHWARTZ, J.M.; FINSON, N. et al. Inheritance of resistance to Bacillus thuringiensis in diamondback moth (Lepidoptera: Plutellidae). Journal of Economic Entomology, v.85, n.4, p. 1046-1055, Aug. 1992.

TAKAKI, S.C.; SCHMIDT, F.B.; BERGAMIN, M.C. et al. Subsídios para um programa de manejo da resistência de Spodoptera frugiperda ao piretróide lambdacialotrina. In: 17 CONGRESSO BRASILEIRO DE ENTOMOLOGIA; 8 ENCONTRO NACIONAL DE FITOSSANITARISTAS, 8, Rio de Janeiro, 1998. Resumos. Rio de Janeiro: USP, 1998. p.586.

TAN, J.G.; McCAFFERY, A.R. Expression and inheritance of nerve insensivity resistance in larvae of Helicoverpa armigera (Lepidoptera: Noctuidae) from China. Pesticide Science, v.55, p.617-625, 1999.

TANG, J.D.; GILBOA, S.; ROUSH, R.T. et al. Inheritance, stability, and lack-of-fitness costs of field-selected resistance to Bacillus thuringiensis in diamondback moth (Lepidoptera: Plutellidae) from Florida. Journal of Economic Entomology, v.90, n.3, p.732-741, Jun. 1997.

THOMAS, J.G.; BRAZZEL, J.R. A comparative study of certain biological phenomena of a resistant and a susceptible strain of the boll weevil, Anthonomus grandis. Journal of Economic Entomology, v. 54, n.3, p.417-420, Jun. 1961.

TSUKAMOTO, M. Methods of genetic analysis of insecticide resistance. In: GEORGHIOU, G.P.; SAITO, T. (Ed.) Pest resistance to pesticides. New York: Plenum, 1983. p. 71-98. 
UYENOYAMA, M.K. Pleiotropy and the evolution of genetic systems conferring resistance to pesticides. In: NATIONAL RESEARCH COUNCIL. Pesticide resistance: strategies and tactics for management. Washington: National Academy Press, 1986. p.207-221.

VARZANDEH, M.; BRUCE, W.N.; DECKER, G.C. Resistance to insecticides as a factor influencing the biotic potential of the house fly. Journal of Economic Entomology, v.47, n.1, p.129-134, Feb. 1954.

WHITTEN, C.J. Inheritance of methyl parathion resistance in tobacco budworm larvae. Journal of Economic Entomology, v.71, p.971-974, Dec. 1978.

WILLINK, E.; OSORES, V.M.; COSTILLA, M.A. El gusano"cogollero" del maiz. Avance Agroindustrial, p.3-7, Jul. 1991.

YOUNG, J.R.; McMILLIAN, W.W. Differential feeding by two strains of fall armyworm larvae on carbaryl treated surfaces. Journal of Economic Entomology, v.72, p.202-203, Apr. 1979.

YU, S.J. Age variation in insecticide susceptibility and detoxification capacity of fall armyworm (Lepidoptera: Noctuidae) larvae. Journal of Economic Entomology, v.76, p.219-222, Apr. 1983.

YU, S.J. Insecticide resistance in the fall armyworm Spodoptera frugiperda (J.E. Smith). Pesticide Biochemistry and Physiology, v.39, n.1, p.84-91, 1991.

YU, S.J. Detection and biochemical characterization of insecticide resistance in fall armyworm (Lepidoptera: Noctuidae). Journal of Economic Entomology, v.85, n.3, p.675-682, Jun. 1992.

YU, S.J. Inheritance of insecticide resistance and microsomal oxidases in the diamondback moth (Lepidoptera: Yponomeutidae). Journal of Economic Entomology, v.86, n.3, p.680-683, Jun. 1993. 
YU, S.J.; NGUYEN, S.N. Inheritance of carbaryl resistance and microsomal oxidases in the fall armyworm (Lepidoptera: Noctuidae). Journal of Economic Entomology, v.87, n.2, p.301-304, Apr. 1994. 